\title{
Les Galates en Asie mineure au regard de la culture matérielle. Hellénisation, maintien, acculturation?
}

\section{Kevin Parachaud}

\section{Q OpenEdition}

1 Journals

Édition électronique

URL : https://journals.openedition.org/anatoliaantiqua/548

DOI : 10.4000/anatoliaantiqua.548

Éditeur

IFEA

Édition imprimée

Date de publication : 1 décembre 2018

Pagination : 23-44

ISBN : 9782362450747

ISSN : 1018-1946

\section{Référence électronique}

Kevin Parachaud, «Les Galates en Asie mineure au regard de la culture matérielle. Hellénisation, maintien, acculturation? », Anatolia Antiqua [En ligne], XXVI | 2018, mis en ligne le 18 juillet 2019, consulté le 03 septembre 2021. URL : http://journals.openedition.org/anatoliaantiqua/548; DOI : https://doi.org/10.4000/anatoliaantiqua.548 


\section{ANATOLIA ANTIQUA ESKI ANADOLU}

\section{XXVI}

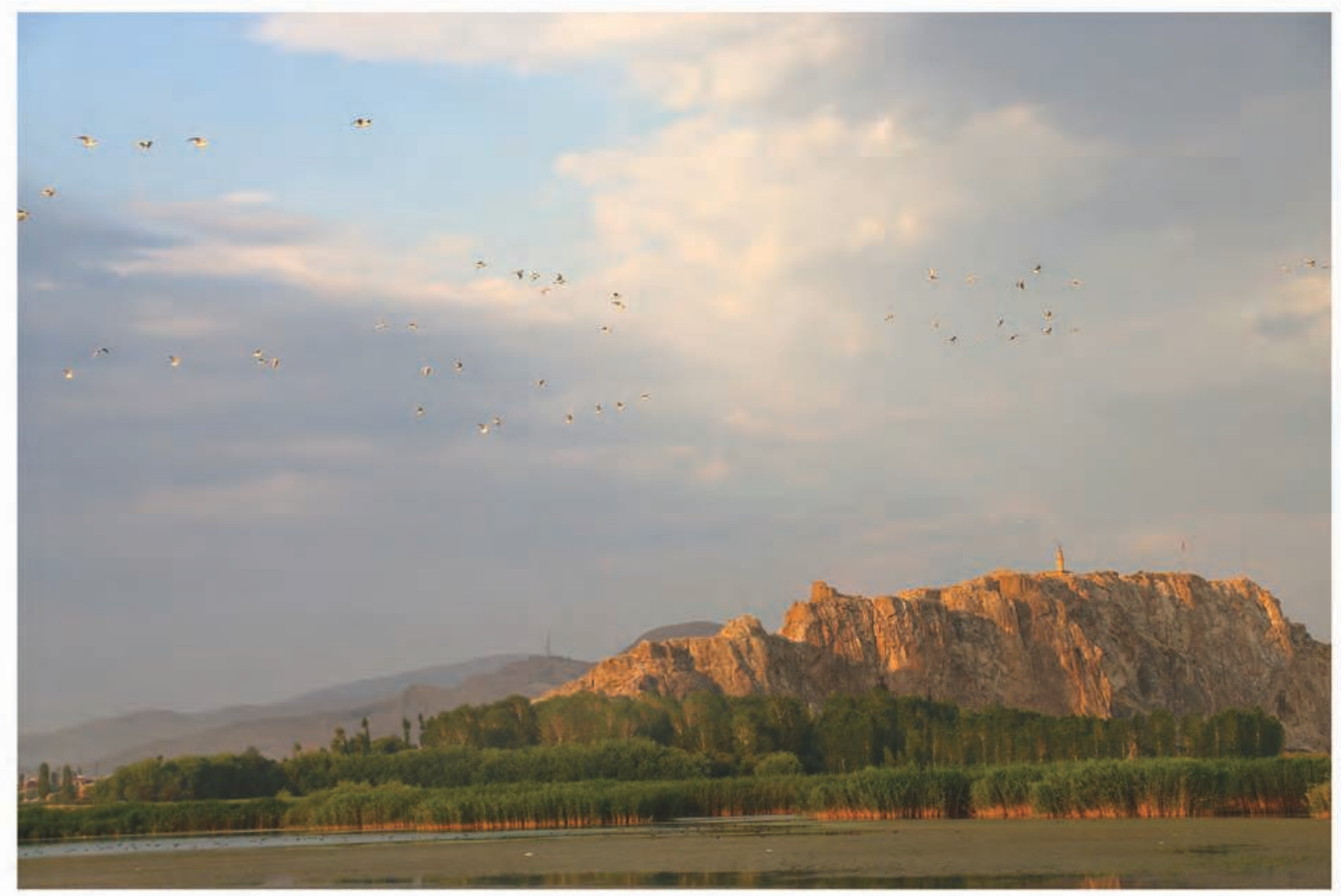

INSTITUT FRANÇAIS D'ETUDES ANATOLIENNES GEORGES-DUMEZIL

CNRS USR 3131

DE BOCCARD 


\section{TABLE DES MATIERES}

Alice VINET et Denis GUILBEAU

A First Glimpse of the Late Neolithic and Early Chalcolithic in Cappadocia through the Lithic

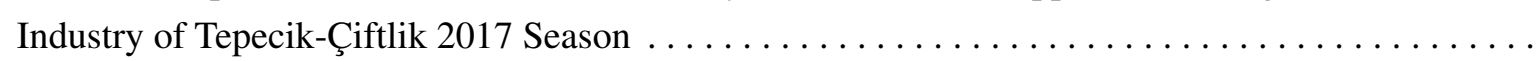

Ergül KODAŞ, Haluk SAĞLAMTIMUR et Yılmaz Selim ERDAL

Three Human Graves of the Hassuna Culture in Türbe Höyük

\section{Kevin PARACHAUD}

Les Galates en Asie Mineure au regard de la culture matérielle. Hellénisation, maintien, acculturation ? 23

H. Asena KIZILARSLANOĞLU et Erkan ALKAÇ

Hellenistic Amphora Stamps from Elaiussa . . . . . . . . . . . . . . . . . . . . .

Aygün EKİN MERİÇ

Late Roman Pottery from the Theatre of Nicaea in Bithynia $\ldots \ldots \ldots \ldots \ldots \ldots \ldots \ldots \ldots$

Nergis GÜNSENIN

La typologie des amphores Günsenin. Une mise au point nouvelle.

Nergis GÜNSENIN et Alessandra RICCI

Les amphores Günsenin IV à Küçükyalı (Istanbul). Un voyage entre monastères ? . . . . . . . . . .

\section{CHRONIQUES DES TRAVAUX ARCHEOLOGIQUES EN TURQUIE 2017}

Erkan KONYAR, Bülent GENÇ, H. Banu KONYAR, Armağan TAN et Can AVCI

Excavations at the Old City, Fortress, and Mound of Van: Work in 2017 . . . . . . . . . . . . . .

\section{Çiğdem MANER}

Preliminary Report on the Fifth Season of the Konya Ereğli, Karapınar, Halkapınar and

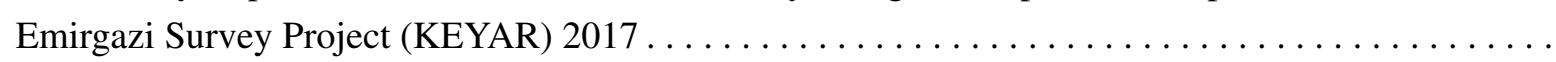

Abuzer KIZIL, Koray KONUK, Taylan DOĞAN, Didier LAROCHE, Enora LE QUERE,

Vasilica LUNGU, Francis PROST et Baptiste VERGNAUD

Eurômos : Rapport préliminaire sur les travaux réalisés en 2017

Olivier HENRY et E. ANDERSSON, J. BLID, Chr. BOST, Ö. ÇAKMAKLI, N. CARLESS-UNWIN, G. ÇİMEN, A. EYİGÖR, A. FRECCERO, A. FREJMAN, Cr. GEORGESCU, E. GOUSSARD, A.-M. GUIMIER-SORBETS, M. HAUCHART, R. HEDLUNG, N. LAMARE, V. LUNGU, Fr. MARCHAND-BEAULIEU, A. SITZ, I. STOJANOVIC, B. VERGNAUD 


\section{LES GALATES EN ASIE MINEURE AU REGARD DE LA CULTURE MATERIELLE. HELLENISATION, MAINTIEN, ACCULTURATION ?}

L'Asie Mineure est un espace soumis aux présences celtiques dès le début de la période hellénistique. Après la mort d'Alexandre, les conflits entre diadoques dans cette région entrainent une importante recrudescence de la circulation de mercenaires celtes ${ }^{1}$, tandis qu'en $280^{2}$, une triple invasion simultanée de la Thrace, de la Grèce et de la Macédoine finit par entrainer, aux environs de 260, l'installation pérenne en Anatolie centrale de populations celtes, les Galates ${ }^{3}$. Si les présences galates en Asie Mineure sont relativement bien documentées et étudiées sur le plan historique, l'approche archéologique a été, quant à elle, insuffisamment exploitée. Nous proposons ici une synthèse de l'historiographie consacrée à cette question archéologique, ainsi qu'une nouvelle étude de l'ensemble des vestiges matériels liés à ces présences celtiques (Fig. 1). Nous interrogerons les rapports à l'identité que peuvent traduire ces témoins des cultures matérielles des Celtes orientaux, en cherchant notamment à observer à la fois les marqueurs d'un maintien des cultures celtiques, ainsi que ceux qui relèvent de phénomènes d'acculturation. Il est également nécessaire de se demander si ces phénomènes, qui ont longtemps été décrits comme totalement asymétriques, ne permettent pas d'envisager des réciprocités plus équilibrées et ainsi offrir un regard renouvelé sur les relations entre les mondes celtique et hellénistique en Anatolie.

\section{HISTORIOGRAPHIE DE L'ETUDE ARCHEOLOGIQUE DES PRESENCES CELTIQUES EN ASIE MINEURE}

L'étude de la culture matérielle des Celtes anatoliens hérite d'une historiographie complexe. De forts présupposés ethnocentrés ont amené certains chercheurs à postuler l'hellénisation rapide des Galates et de leur culture matérielle. Associés à une effective rareté des données archéologiques, cette approche a ainsi tenté de transformer une absence de preuve en une preuve de l'absence. A l'inverse, une interprétation diffusionniste a conduit d'autres travaux à proposer une identification erronée de vestiges archéologiques liés aux présences galates. Néanmoins, ce sujet a également fait l'objet d'importantes publications, principalement de la part d'archéologues allemands connaisseurs à la fois de l'Asie Mineure hellénistique et de l'Europe laténienne, grâce auxquels nous pouvons aujourd'hui dresser un inventaire des vestiges archéologiques liés aux présences galates en Asie Mineure.

\subsection{Le postulat ethnocentré de l'hellénisation}

L'hellénisation des Galates n'a pas fait l'objet de travaux en soi. Pourtant, cette idée s'est immiscée comme un état de fait, et a particulièrement influencé, consciemment ou non, certains travaux et certaines interprétations concernant la culture matérielle des Celtes anatoliens. Il est donc primordial d'évoquer les biais interprétatifs portés par cette approche et d'en comprendre la portée et les conséquences si l'on veut proposer une analyse renouvelée de cette question.

Jusque dans son nom, le concept d'hellénisation ne prend en compte qu'une dimension unilatérale des influences culturelles, celles-ci ne pouvant aller que dans le sens de la culture grecque vers les autres cultures. Cette vision unilatérale porte en elle un jugement de valeur du "niveau" des sociétés, en cela qu'elle amène à considérer comme inévitable

\footnotetext{
*) Doctorant contractuel - Université de Limoges, CRIHAM - EA 4270 ; membre associé du laboratoire TRACES - UMR 5608, kevin.parachaud@unilim.fr

1) Adam et Fichtl 2011, Baray 2014, 2017a, 2017b.

2) Toutes les dates utilisées sont avant notre ère, sauf mention du contraire ou référence à un contexte contemporain.

3) Le terme "Galate" est un nom générique donné à partir du 3 e siècle par les auteurs grecs aux Celtes avec lesquels ils entrent en contact direct. La première attestation sûre de ce nom est attribuée au poète Callimaque dans son "hymne à Délos" daté des environs de 275. L'usage contemporain, lui, limite ce nom aux groupes celtiques qui se sont installés en Anatolie centrale.
} 


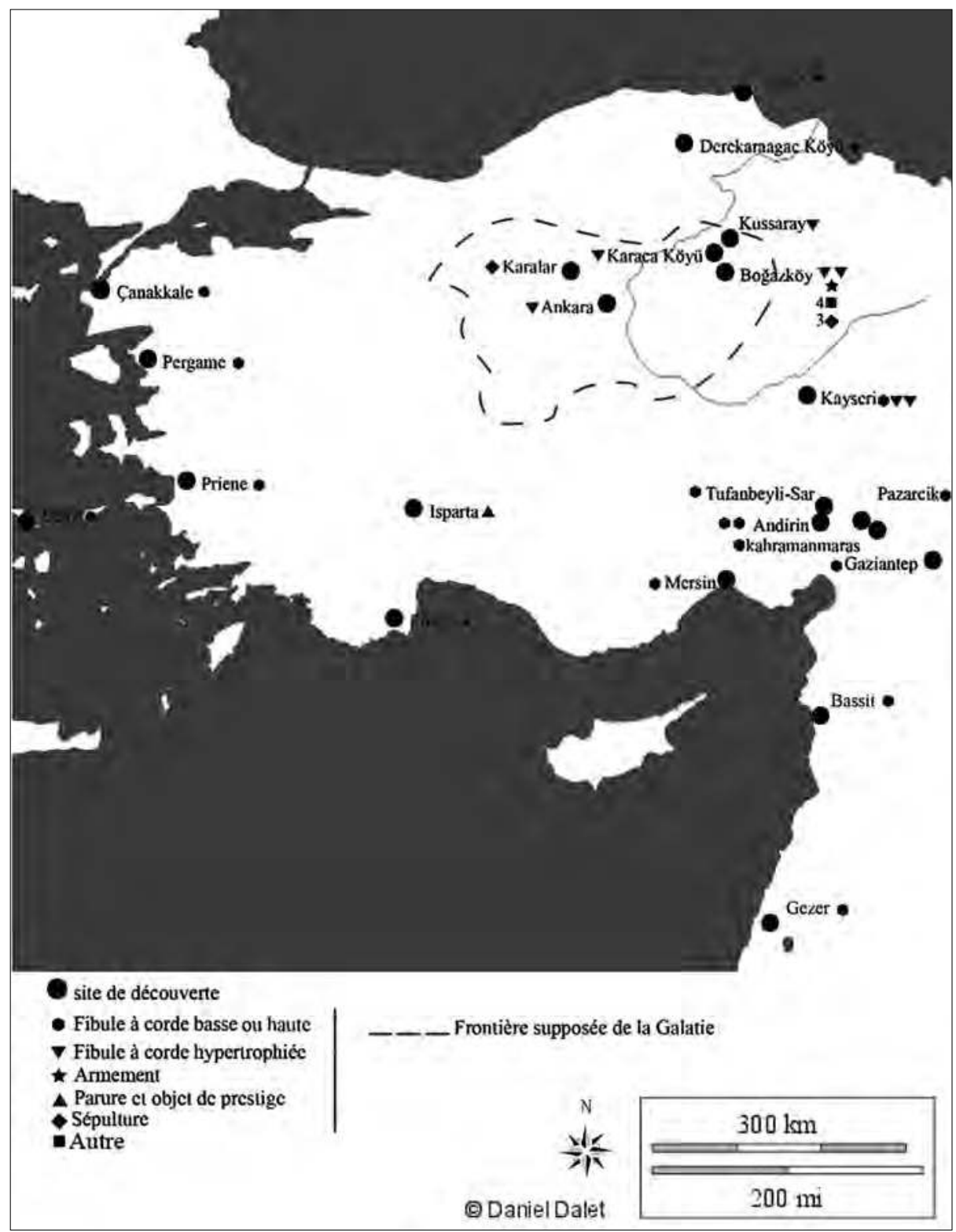

Fig. 1 : Carte de répartition générale des vestiges liés aux présences galates en Asie Mineure.

l'intégration ou l'imitation de la culture grecque par les autres cultures. Cela revient à considérer implicitement la culture grecque comme un modèle supérieur pour lequel l'attrait des autres cultures irait de soi $^{4}$. Bien que remis en cause depuis les années 1980, ce concept est encore parfois utilisé.

Dans le cadre de notre sujet, ce raisonnement sous-entend que si l'on ne connaît que très peu de vestiges laténiens en Asie Mineure, c'est parce que les Galates ont dû adopter les cultures matérielles locales, théorie d'autant plus séduisante que cette culture était vue par beaucoup comme "supérieure". Cette idée de l'hellénisation des Galates est déjà présente dans les sources antiques, où ils sont parfois nommés Gallo-Grecs, car :

"Ce qui est semé en terre étrangère devient ce dont il se nourrit"s.

Victimes des élans de philhellénisme et de nationalisme qui caractérisent grandement les cou-

4) Bats $2006: 32$.

5) Tite-Live, Histoire romaine, XXXVIII, 17. 
rants intellectuels de leur époque, les historiens contemporains du début du $20^{\mathrm{e}}$ siècle ont repris à leur compte les stéréotypes ethniques et les présupposés identitaires des auteurs antiques, et on largement diffusé l'idée que ces "barbares" européens avaient naturellement été assimilés par la supériorité de la culture grecque. Si cette idée n'est plus assumée aussi clairement que sous la plume d'Adolph Reinach, elle est encore partiellement présente aujourd'hui et l'on peut par exemple encore lire que :

"La civilisation matérielle des Galates est très peu connue ; elle a subi évidemment une hellénisation progressive. Séparée du milieu laténien, cette minorité étrangère n'a pas pu marquer la civilisation hellénistique beaucoup plus évoluée"6.

De plus, une autre grille de lecture problématique est induite par le concept d'hellénisation. Puisque ce processus ne peut aller que de la culture grecque vers une autre culture, on ne peut penser la présence d'un vestige étranger en contexte hellénistique que comme le résultat du passage d'un ou plusieurs individus porteurs de cette culture, et non comme la potentielle adoption de cet élément étranger par un individu de culture grecque. Pour notre sujet, cela revient à voir la présence d'objets laténiens comme la preuve de la présence ou du passage d'individus porteurs de cultures matérielles laténiennes, et non comme la possible diffusion, d'objets laténiens dans le monde hellénistique.

\subsection{L'approche diffusionniste vectrice d'identifications erronées}

La première étude archéologique consacrée à notre sujet est celle de Robert Zahn, en 1907, à propos d'un type de céramique peinte qu'il considère comme galate.

Suite aux fouilles des sites de Boğazköy et de Gordion, Robert Zahn identifie un type de céramique peinte caractérisée par différents types de décors géométriques, généralement en triangles ou en spirales, et différentes couleurs récurrentes comme le rouge brun et le brun foncé, sur un fond blanc ${ }^{7}$. Zahn relie cette céramique, au nom "d'évidentes similitudes", à des produits de La Tène finale datant du $1^{\text {er }}$ siècle, découverts dans la région du Rhein-
Main et au Hradischt de Stradonitz en Bohême ainsi qu'en Gaule, comme à Bibracte ${ }^{8}$.

Cette première étude de Robert Zahn fera autorité pendant de nombreuses années, faute d'avoir été rediscutée. Elle sera tour à tour mise en doute puis réhabilitée par Ferdinand Maier en 1963 puis Kurt Bittel en 1974, mais la publication la plus récente sur le sujet est celle de Mehmet et Nesrin Özsait, de 2003, qui met définitivement à mal l'hypothèse originelle de Zahn. Cet article met en avant l'existence de liens entre la céramique hellénistique d'Anatolie (dont la céramique dite "galate") et une tradition régionale remontant à l'âge du Fer, principalement dans les décors et les formes ${ }^{9}$. Quant à l'application de décor sur fond blanc, ces chercheurs envisagent qu'il s'agisse d'un style hérité de la céramique phrygienne, elle-même héritée de la céramique cappadocienne du $2^{\mathrm{e}}$ millénaire ${ }^{10}$ (Fig. 2). Pourtant, malgré l'apport de cette publication, la céramique dite "galate" est encore considérée comme telle par certains chercheurs s'intéressant aux présences celtiques en Asie Mineure ${ }^{11}$.

On peut en effet reconnaître, comme le pensaient Robert Zahn et Kurt Bittel, qu'il y a bien une ressemblance stylistique entre la céramique dite galate et un type de céramique peinte laténienne; on connaît en effet des vases recouverts d'un engobe blanc uni dont le champ est limité par deux zones rouges ou brunes, parfois avec addition de dessins géométriques de couleur brune, bistrée ou violacée, tracés au pinceau sur le fond blanc de l'engobe $^{12}$. Cependant en Asie Mineure ce type de couleurs et de décors est avant tout une tradition commune à l'ensemble de l'Anatolie, et ce, depuis l'âge du Bronze. Il ne s'agit donc pas d'un lien avec la céramique laténienne, mais d'un lien avec une très ancienne tradition locale de céramique peinte que l'on retrouve au sein de plusieurs cultures matérielles anatoliennes depuis le $2^{\mathrm{e}}$ millénaire.

De plus, si ces ornements géométriques peuvent trouver des similitudes avec des céramiques laténiennes, la céramique dite "galate" connaît également un deuxième grand type de décor fait de motifs végétalisants. On y retrouve un motif d'arbre ou d'arbuste dont l'origine remonte au moins à l'âge du Fer anatolien $\left(7^{\mathrm{e}}-6^{\mathrm{e}}\right.$ siècle $)$, le motif du lierre qui est un motif très prisé dans la région depuis le $6^{\mathrm{e}}$ siècle ou encore les représentations de bourgeons

7) Zahn $1907: 228$.

8) Zahn $1907: 227$

9) Özsait et Özsait $2003: 325$.

10) Özsait et Özsait $2003: 323$.

11) Voigt $2002: 17$.

12) Déchelette 1914 : 996-997. 


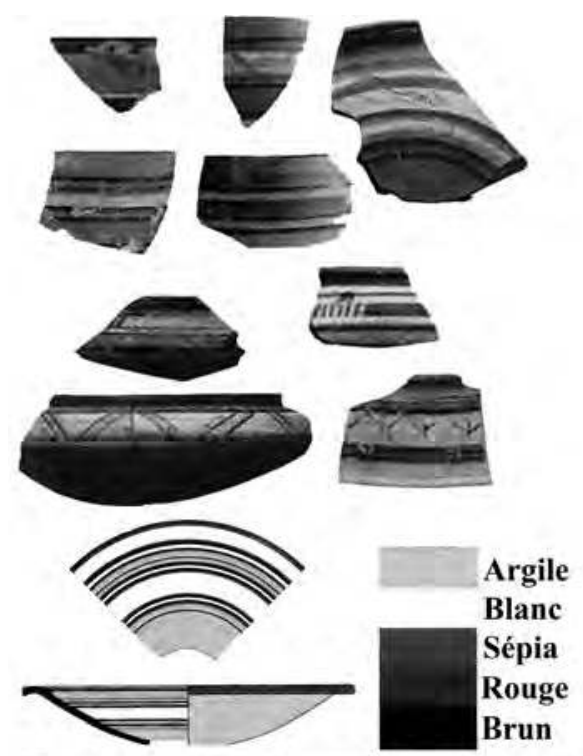

Sélection de fragments de céramique "dite galate" (d'après Maïer, 1963).

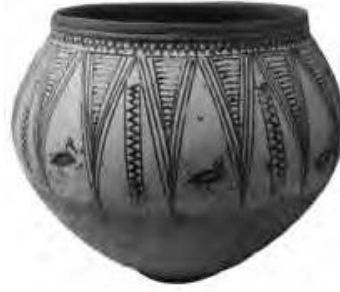

I

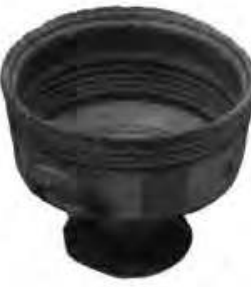

II

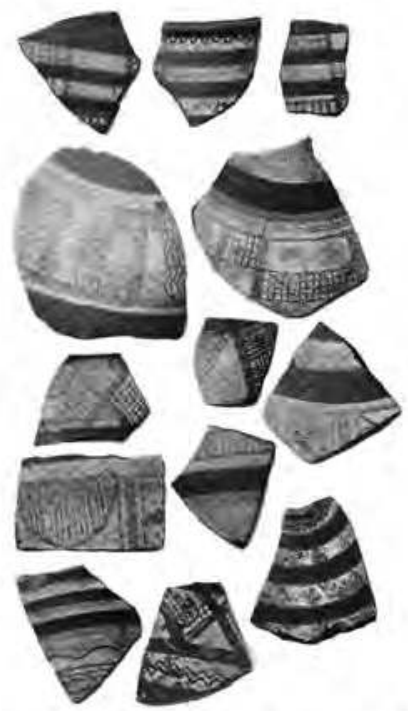

sélection de fragments de céramiques laténiennes possédants des similitudes avec la céramique "dite galate" (d'après Pič, 1906).

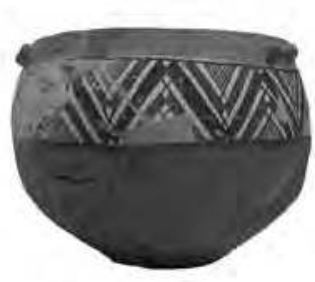

III

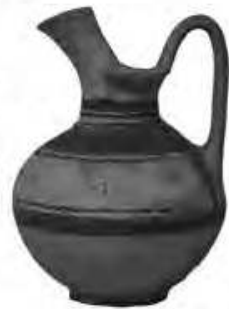

IV

Sélection de céramiques anatoliennes (musée archéologique d'Istanbul, photographies personnelles)

I : Nord-Est de l'Anatolie, Âge du bronze moyen-récent (Ile millénaire)

II : Chypre, période géométrique (1050-750) III et

IV : Boğazköy, âge du Fer (VIIe-VIe siècle)

Fig. 2 : Illustrations des comparaisons entre les céramiques dites "galates", laténiennes et anatoliennes.

et feuilles caractéristique du style hellénistique ${ }^{13}$. On voit également sur quelques rares exemples des représentations zoomorphes, comme sur un lagynos de Sivas ${ }^{14}$. Ce sont des motifs bien connus, et largement représentés dans l'art hellénistique ${ }^{15}$. Or ce genre de motif est totalement absent de la céramique peinte laténienne.

Mais le principal argument plaidant en défaveur de l'interprétation originelle de Robert Zahn est d'ordre chronologique. Si l'on suit le raisonnement proposé, les Galates auraient apporté et diffusé leurs traditions de céramiques peintes, ce qui aurait entrainé la production de la céramique dite "galate". Seulement, si l'on admet cette interprétation, alors on admet, de fait, que les secondes sont postérieures aux premières. Or, les archéologues connaisseurs de cette céramique anatolienne considèrent tous qu'elle se développe dans le courant du $3^{\mathrm{e}}$ siècle $^{16}$, période à laquelle il n'y a pas de céramiques de ce type en Europe laténienne ; celles-ci n'apparaissent en effet qu'au $1^{\text {er }}$ siècle. Qu'il s'agisse donc des décors, des couleurs, ou de la chronologie, on ne peut voir de lien probant entre la céramique dite "galate" et la céramique laténienne. Il semble donc nécessaire de réfuter la filiation culturelle proposée pour cette céramique, dont la distribution dépasse par ailleurs la seule Galatie et se retrouve jusqu'aux bords de la mer Noire.

13) Özsait et Özsait $2003: 331$.

14) Maïer $1963: 246$.

15) Özsait et Özsait $2003: 330$.

16) Özsait et Özsait $2003: 323-325$. 
Un autre dossier majeur mérite lui aussi d'être rediscuté, celui du tumulus "galate" de Bolu. En 1964, deux tumuli ont été fouillés à $8 \mathrm{~km}$ au Sud du village actuel de Bolu, situé dans l'ancienne Bithynie. Si l'un a été totalement pillé, le second a livré un riche mobilier ${ }^{17}$. Si la plupart de ces pièces, en l'occurrence deux bracelets en or, un bol et une patère en argent et un mors en bronze répondent à des typologies tout à fait caractéristiques des cultures matérielles hellénistiques, la présence de deux torques et d'un disque orné en or a permis de voir ce tumulus comme la sépulture d'un Galate.

Le torque est certes, dans l'iconographie hellénistique, une caractéristique des personnages celtes. Il faut pourtant rappeler qu'en réalité cette parure n'en est pas l'apanage absolu ; d'autres peuples ont utilisé ce type de parure, comme les Thraces, les Grecs, les Perses ou les Scythes. La seule présence de ces objets ne suffit donc absolument pas pour apposer une identité celtique à leur propriétaire. De plus, typologiquement, les torques de Bolu ne connaissent pas d'équivalent européen convaincant. Le premier, fait d'un jonc torsadé et de deux extrémités lisses en pointe, ne connaît tout simplement aucun élément de comparaison parmi les productions laténiennes. Le second, formé d'un simple jonc lisse et circulaire sans extrémités ornées, peut ressembler à certains exemplaires datés de $\mathrm{La}$ Tène A, comme ceux d'Acy Romance ou de SaintMemmie $^{18}$, mais ces exemplaires sont trop anciens pour représenter une comparaison convaincante.

Vient alors la question du disque en or (Fig. 3). Cet objet est, selon Kurt Bittel et Nezih Firatl1 ${ }^{19}$, l'objet le plus important du mobilier funéraire, car il serait le seul qui permettrait véritablement d'identifier cette sépulture comme celle d'un Galate ${ }^{20}$. On voit au centre de ce disque de $7,1 \mathrm{~cm}$ de diamètre le visage d'un homme dont la représentation a été interprétée comme l'image traditionnelle du "barbare" dans l'art hellénistique, principalement au regard de la moustache, qui rappellerait celle du "Galate mourant" de Pergame. Pourtant la présence de cette moustache n'est pas assurée, les photographies accessibles de cette pièce ne sont pas suffisamment de bonne qualité pour confirmer la présence d'incisions au-dessus des lèvres. Il serait nécessaire de repartir de l'objet en lui-même pour en fournir une analyse convaincante.
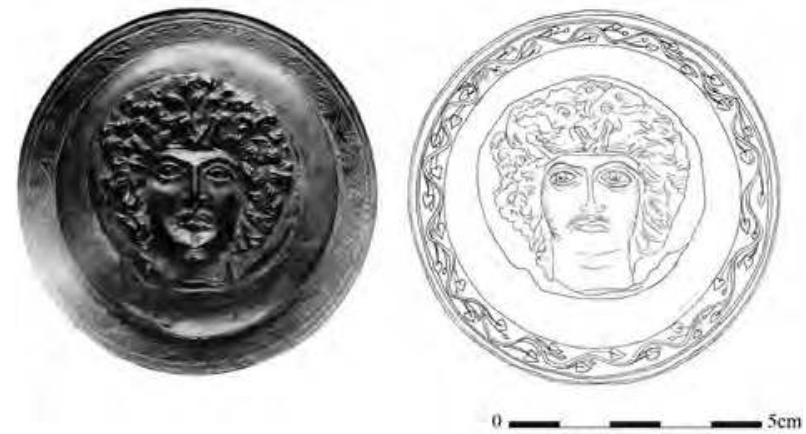

Fig. 3 : Le disque en or de Bolu (d'après Fıratlı 1964).

Ensuite, si le torque emblématique des représentations hellénistiques de Celtes est ici absent, le personnage porte en revanche une autre parure : il arbore sur son front, parmi son épaisse chevelure, un diadème composé d'un fin tour de tête avec au centre un appendice en forme de "V" au niveau du front ${ }^{21}$. Ce détail est loin d'être anodin, car il s'agit, avec la bague et la robe, de l'attribut par excellence de la royauté hellénistique, insigne que le roi lègue à son successeur pour matérialiser son choix ; il aurait même un caractère sacralisant ${ }^{22}$.

La composition du mobilier funéraire de Bolu, étudiée individuellement, ne fournit donc aucun argument en faveur de l'identification d'une sépulture galate ou d'un objet pouvant se rattacher à la culture matérielle laténienne.

Nous voyons que ces deux grands dossiers que sont la céramique dite "galate" et le tumulus de Bolu pêchent tous deux par le même biais. Avec une approche diffusionniste et un postulat du lien de ces vestiges avec les présences celtiques, l'analyse ne se tourne que vers les exemples qui peuvent aller dans le sens du postulat initial. Ce biais de confirmation a détourné l'analyse des éléments de comparaison venant, eux, des cultures matérielles locales, alors même que ceux-ci représentaient des comparaisons plus nombreuses, plus précises, et plus anciennes.

\subsection{Identifications et études de mobiliers laténiens en Asie Mineure}

Le corpus présenté dans cet article est un répertoire a priori complet des données connues grâce aux publications antérieures. Nous exposerons ici

17) Firatlı $1965: 365$.

18) Chapry $2014: 115$.

19) Firatl1 1965, Bittel 1976.

20) Firatl $1965: 366$, Bittel $1976: 245$.

21) Firatl $1965: 366$.

22) Préaux $1978: 184-185$. 
les analyses et les interprétations proposées par ces précédentes études, afin de voir dans quelle mesure ce travail, s'il s'inscrit dans une certaine continuité de la recherche, offre toutefois un regard renouvelé de ces données archéologiques.

Le corpus des fibules est de loin le plus important. Selon Kurt Bittel, à qui nous devons la première publication sur le sujet ${ }^{23}$, le critère principal de classification de ces fibules, qui sont toutes de schéma La Tène moyenne, est le système par lequel le pied s'attache sur l'arc ; il distingue ainsi 2 groupes, celui où le pied s'enroule en épissure (Windungen) autour de l'arc, et celui où le pied s'accroche par une ou deux languettes (Laschen $)^{24}$. Il remarque également un autre critère particulier sur certaines fibules, une corde externe singulièrement haute (oberer Sehne), que l'on ne retrouve pas parmi les productions européennes $^{25}$. En 1978, Hartmut Polenz propose une nouvelle analyse qui reprend les distinctions typologiques identifiées par Kurt Bittel, mais insiste sur la différence entre corde haute et corde basse ; il s'agit pour lui du critère le plus important, car les cordes hautes, qui n'ont pas de parallèle en Europe, pourraient permettre d'identifier le premier exemple archéologique de vestige laténien spécifique à l'Anatolie. Concernant la répartition de ces fibules, Hartmut Polenz remarque que ces pièces sont présentes dans deux espaces différents; les fibules à cordes basses se retrouvent selon lui sur des sites le long de la côte méditerranéenne, et les fibules à corde haute dans une région à l'intérieur des terres correspondant peu ou prou au territoire de la Galatie. Andreas Müller Karpe, par la suite, étend le domaine côtier jusqu'au Sud-Est de la boucle du Kizilırmak ${ }^{26}$.

Concernant les trois parures de notre corpus, la pièce la mieux connue est une parure annulaire à oves creux et à décor plastique, dite originaire des environs de Finike (corpus $n^{\circ} 13$ ). Principalement étudiée par Ulrich Schaaf en 1972, son analyse typologique se concentre sur son décor plastique, qu'il présente comme unique, sans équivalent en Europe laténienne. Il date cet anneau du $3^{\mathrm{e}}$ siècle $^{27}$. Ensuite, nous devons à Andréas Müller-Karpe la publication de deux parures supplémentaires. La première, provenant des environs d'Isparta (corpus $n^{\circ} 16$ ), est vue par Müller-Karpe comme une forme hybride entre deux types connus en Europe laténienne, les anneaux où se suivent des rangées de trois petites nodosités, et les parures, plus rares, faites d'une succession de bossettes ${ }^{28}$. La seconde pièce (corpus $\mathrm{n}^{\circ} 2$ ) ne dispose pas de contexte de découverte connu, considéré en "Asie Mineure". Nous savons uniquement qu'il s'agit d'un anneau à nodosités, qu'Andréas Müller-Karpe date également du $3^{\text {e }}$ siècle.

Si nous nous accordons avec les méthodes analytiques proposées par ces publications antérieures, il nous semble que leurs interprétations, en revanche, reposent sur une importante subordination aux sources antiques, et sont parfois influencées par des postulats problématiques. Ces travaux ont souvent essayé, en croisant la datation avec la localisation, de déterminer quel événement historique pouvait expliquer la présence de tel ou tel objet ; et lorsqu'aucun ne correspondait, des justifications anecdotiques ont été avancées, comme le passage d'un individu isolé. Ce procédé peut induire deux principaux biais méthodologiques. Tout d'abord, on voit que c'est parfois le lien avec un événement historique qui vient influencer l'analyse typologique ou la datation de ces pièces, et non pas l'inverse. Par exemple, la parure à oves creux de Finike a été datée par Ulrich Schaaf de la première moitié du $3^{\mathrm{e}}$ siècle, principalement au regard du fait que cela correspondait à la période des excursions militaires galates sur les côtes anatoliennes. Ensuite, cette méthode empêche de détacher ces objets de l'histoire des présences celtiques en Asie Mineure, et impose donc de voir dans chaque vestige le passage d'un Celte. Ce postulat ne permet alors pas d'envisager d'autres modes de diffusion, comme le commerce, ou la production locale d'objets laténiens, ce qui biaise la façon dont on pense les relations entre mondes galate et hellénistique en Asie Mineure. Par ailleurs, en filigrane, ne pas concevoir la circulation de ces vestiges par un autre vecteur qu'un porteur d'origine celtique sous-entend, de fait, que l'on n'envisage pas la possibilité de l'adoption par des populations hellénistiques d'objets laténiens. Ce biais méthodologique fausse l'analyse du rapport à l'identité que l'on peut faire de ces pièces.

25) Bittel $1969: 45$.

26) Müller-Karpe $1988: 193$.

27) Schaaf $1972: 97$.

28) Müller-Karpe $1988: 195$. 


\section{LE MAINTIEN D'UNE CULTURE MATERIELLE LATENIENNE EN ASIE MINEURE}

Des vestiges matériels laténiens en Asie Mineure, nous ne connaissons pour l'heure que 27 fibules, 3 parures et une panoplie d'arme. Il s'agit en effet d'un corpus limité, pour lequel il serait tentant d'avancer l'hypothèse du remplacement de la culture matérielle laténienne d'origine des Galates par une culture matérielle hellénistique locale. Pourtant une analyse typologique et chronologique de ces pièces permet de démontrer le maintien, sur le long terme, de mobiliers laténiens et, plus intéressant encore, l'émergence d'un faciès régional inédit.

\subsection{Identification d'un maintien tardif de certains faciès laténiens}

Si l'on avance l'hypothèse d'une hellénisation rapide de la culture matérielle des Galates à la suite de leur passage en Anatolie, on s'attendrait alors à observer une grande majorité d'objets laténiens correspondant à la période de leur arrivée (ce qui correspond, en chronologie relative ${ }^{29}$, à la période fin LT B2 - première moitié de LT C1), puis une décroissance progressive et rapide du nombre de vestiges aux périodes suivantes. Or, l'analyse typo-chronologique des données de notre corpus contredit cette hypothèse.

Une très large majorité de nos données sont sans contexte de découverte précis, parfois sans même une localisation approximative. Dès lors, l'approche typo-chronologique par comparaison avec les typologies européennes est la seule permise pour donner une datation à ces objets. Cette méthode est également celle employée par les études antérieures, et nous nous accordons avec la plupart des datations proposées ; nous n'analyserons ici que les pièces pour lesquelles ces travaux n'ont pas fourni de chronologie précise ou qui ont proposé des datations possiblement erronées (Fig. 4).

La fibule d'Andirin AND I (corpus ${ }^{\circ} 6$ ) avait été datée de la période LT $\mathrm{C}^{30}$. En effet le porte-ardillon est assez long, presque la moitié de la longueur totale, ce qui semble correspondre à cette période. Cependant, cette pièce possède un arc semi-circulaire plus haut que les standards de LT C1, et se rapproche plus des arcs caractéristiques de
LT D1; il semble que cette datation soit plus appropriée.

Ensuite, il est surprenant de remarquer que les fibules de Kahramanmaraş (corpus $n^{\circ} 17$ ) et Pazarcık (corpus $\mathrm{n}^{\circ} 24$ ) ne se voient pas accorder la même datation $^{31}$, alors qu'elles sont typologiquement semblables. L'arc trapézoïdal ouvert, ainsi que les fortes similitudes avec l'exemplaire d'Asie Mineure AM III (corpus $n^{\circ} 4$ ), nous permettent de dater plutôt la pièce de Kahramanmaraş de LT C2.

Sur la fibule de Priène (corpus $n^{\circ} 26$ ) la longueur restituée du porte-ardillon paraît trop courte pour un exemplaire daté de prime abord de $\mathrm{LT} \mathrm{C}^{32}$, période où les porte-ardillons sont aussi longs voir plus longs que l'arc. De plus, l'arc trapézoïdal ouvert semble également assez haut, alors qu'ils sont généralement écrasés pendant LT C1. Il est donc permis de douter de cette chronologie, et de rapprocher cette pièce des standards de LT C2.

La pièce de Kayseri KAY I (corpus $n^{\circ} 19$ ) avait été datée de $\mathrm{LT} \mathrm{C} 1^{33}$. Ici, l'analyse est la même que pour la pièce AND I, ses caractéristiques pourraient correspondre en effet aux standards de cette période, mais également à ceux de LT C2. Son arc est légèrement plongeant et assez haut par rapport aux standards de la période LT C1, nous pensons donc qu'il est plus judicieux de privilégier la seconde datation.

La fibule de Karaca Köyü (corpus ${ }^{\circ} 18$ ) a été considérée équivalente, chronologiquement, à la pièce de Boğazköy BOG I (corpus $\left.\mathrm{n}^{\circ} 17\right)^{34}$, datée grâce à son contexte de la période LT D2a. Pourtant, la pièce de Karaca Köyü, elle, possède un arc semi-circulaire surélevé plutôt caractéristique de la période LT D1.

Ensuite, on voit que les fibules de Délos (corpus $n^{\circ} 1$ ), de Gaziantep (corpus $n^{\circ} 14$ ) et de Derekaraağac Köyü (corpus $n^{\circ}$ 9) n'ont pas, dans les recherches antérieures, été accompagnées de datations précises. Il est possible d'envisager pour ces pièces les datations suivantes : la pièce de Gaziantep possède un arc en étrier relativement haut, ce qui semble bien indiquer que cette pièce est proche des fibules de la période LT D1. Quant à la pièce de Délos, le porte-ardillon relativement court ainsi que la hauteur et la forme de l'arc plaide plutôt pour une datation à LT C2 ou fin LT C1. La pièce de Derakaraağaç Köyü, elle, peut assez sûrement être consi-

29) Le système de chronologie relative utilisé dans cette étude correspond à celui proposé par G. Kaenel en 1990.

30) Müller-Karpe $1988: 192$.

31) Müller-Karpe $1988:$ 192-193.

32) Bittel 1969: 47.

33) Bittel $1969: 47$

34) Müller-Karpe $1988: 192$ 


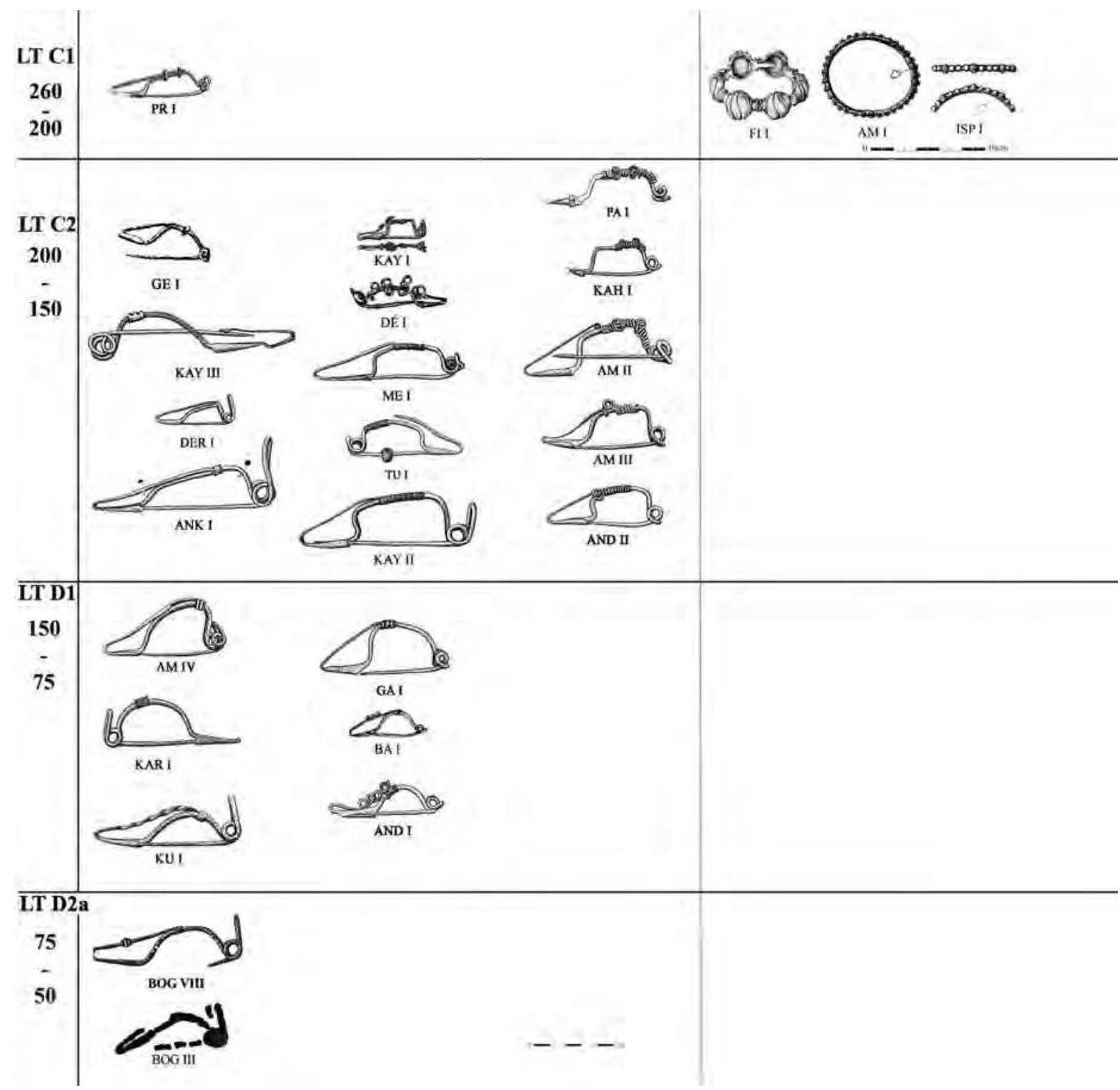

Fig. 4 : Tableau de classification typo-chronologique des fibules et parures laténiennes d'Asie Mineure.

dérée comme une pièce typique des productions laténiennes de LT C2. On retrouve, comme sur la pièce d'Ankara (corpus $n^{\circ} 8$ ), le même arc trapézoïdal ouvert plongeant vers l'avant, le pied rectiligne et le porte-ardillon court typique de cette période.

Concernant les parures, la pièce dite de Finike (corpus $\mathrm{n}^{\circ} 13$ ) est plus compliquée à dater. Les parures à plus de dix oves apparaissent à LT B2a, celles ayant entre neuf et cinq oves se développent à partir de LT B2b, et celles à quatre ou trois oves à partir de LT $\mathrm{C1}^{35}$. Ensuite, on trouve en Bohême des anneaux de chevilles à six ou sept oves à dé- cor "plastique" associés aux dernières fibules à pied libre et aux premières fibules de schéma La Tène moyenne. On peut donc dater la pièce dite de Finike des environs de fin LT B2 ou début LT C1, bien que cela reste difficile à démontrer, faute de contexte.

Ensuite, au sujet des anneaux à nodosités, nous savons qu'en Europe les parures à pastillage sont connues de LT B2 à LT C1. En l'absence de contexte ou d'autre critère questionnable, nous ne pouvons proposer, pour les pièces d'Asie Mineure AM I (corpus $n^{\circ} 2$ ) et d'Isparta (corpus $n^{\circ} 16$ ), de datation plus précise. De plus, comme pour la pièce 
de Finike, nous avons envisagé que la pièce d'Isparta soit une production locale, ce qui rend sa datation d'autant plus incertaine.

Nous voyons donc que seules les trois parures et potentiellement la fibule de Priène correspondent à la période d'arrivée des populations galates en Asie Mineure. Au contraire, c'est à partir de LT C2, environ deux générations après l'installation des Galates en Anatolie centrale, que l'on observe le plus grand nombre de pièces, et cette présence d'objets laténiens se maintient jusqu'à la période LT D2, ce qui correspond aux environs de la fin de la période d'indépendance de la Galatie. C'est au-delà de l'intégration de ce territoire à l'Empire que l'on observe une absence de vestige laténien. Les données disponibles ne permettent donc d'observer ni déclin ni abandon de ces éléments laténiens. La présence de ces éléments, jusqu'à la fin de l'indépendance galate, plaide en faveur de l'hypothèse d'un maintien au moins partiel, dans le cadre de certains objets caractéristiques, des cultures matérielles laténiennes en Asie Mineure.

\subsection{Emergence d'un faciès laténien régional en Anatolie}

Dès sa première étude, Kurt Bittel avait identifié un critère typologique inédit spécifique aux fibules anatoliennes, la corde externe dite haute, ou oberer Sehne. En réalité, plus qu'une corde externe haute, il est préférable de nommer ce critère typologique "corde externe hypertrophiée", car c'est précisément cette hauteur particulière, égale ou supérieure à celle de l'arc, et non juste une orientation de la corde vers le haut, qui marque la spécificité de cette typologie anatolienne face aux productions européennes. On ne connaît en effet pas, au sein des cultures matérielles laténiennes, de fibule portant une corde de ce type. Ce critère n'est pas non plus le résultat d'une influence ou d'une hybridation avec les productions locales, car on ne retrouve aucun exemple de comparaison similaire au sein des cultures matérielles hellénistiques. De plus, nous voyons que l'aire de diffusion de ces fibules se situe en territoire galate ou dans sa périphérie (Fig. 1) ; donc, plus précisément qu'une "spécificité anatolienne", il faut considérer cette corde externe hypertrophiée, que l'on retrouve en tout sur 8 pièces, comme le marqueur d'une production locale d'objets laténiens, par des artisans galates ou par des autochtones influencés par la culture matérielle de ces derniers. Cette production locale marque le premier exemple de développement d'une typologie laténienne régionale hors d'Europe.

En revanche, les autres fibules laténiennes d'Asie Mineure avaient été interprétées comme des pièces semblables aux typologies européennes, amenées dans cette région par le passage anecdotique d'un individu ${ }^{36}$ ou à la suite d'un événement historique $^{37}$. Pourtant, on observe que les fibules d'Asie Mineure munie d'épissures, les Windungen identifiés par Bittel, sont des exemplaires uniques, différents de leurs équivalents européens (Fig. 5). On distingue différents types d'épissures sur nos fibules. Celui où l'attache du pied forme des "faux ressorts" est le second système le plus représenté de notre corpus (pour les pièces où cette information est identifiable), avec 6 exemplaires. Certes, le style à faux ressort existe bien en Europe laténienne ${ }^{38}$. Cependant on observe une différence typologique précise entre le type européen et le type anatolien. Sur les pièces européennes, les faux ressorts imitent distinctement un ressort de fibule, avec des spires et, surtout, avec une corde externe orientée vers le haut. Nous proposons d'interpréter ce critère comme une démarche stylistique volontaire de l'artisan, qui cherche consciemment à imiter un ressort de fibule. Or, sur les exemplaires anatoliens, cette caractéristique typologique est différente par essence, et parler pour ces pièces de "faux ressorts" semble être un abus de langage. On observe en effet sur ces pièces la présence de spires rappelant celles des faux ressorts européens. Cependant il n'y a pas sur ces ornements la même volonté d'imitation d'un ressort de fibule ; hormis sur la pièce d'Andırın AND I (corpus $n^{\circ} 6$ ) qui représente ici une exception, on ne trouve pas sur ces spires d'enroulement imitant un ressort complet, avec une fausse corde externe. Au contraire, sur les fibules anatoliennes on voit que la dernière spire part sous l'arc et s'enroule autour de lui. Ce détail typologique marque une évolution de ce type à spirales où les spires n'imitent plus un ressort de fibule. Selon notre interprétation, on ne retrouve plus la même volonté stylistique lors de la conception de l'objet. Autre différence typologique d'importance, on voit sur les fibules anatoliennes que les spires s'enroulent autour de l'arc, alors que sur les modèles européens les faux ressorts courent au-dessus de l'arc, avant de venir se fixer à l'arrière de celui-ci. Il serait donc nécessaire de parler, pour les pièces anatoliennes, d'épissures en pseudo faux ressorts, afin de ne pas utiliser un terme connoté pouvant induire un biais d'analyse. 


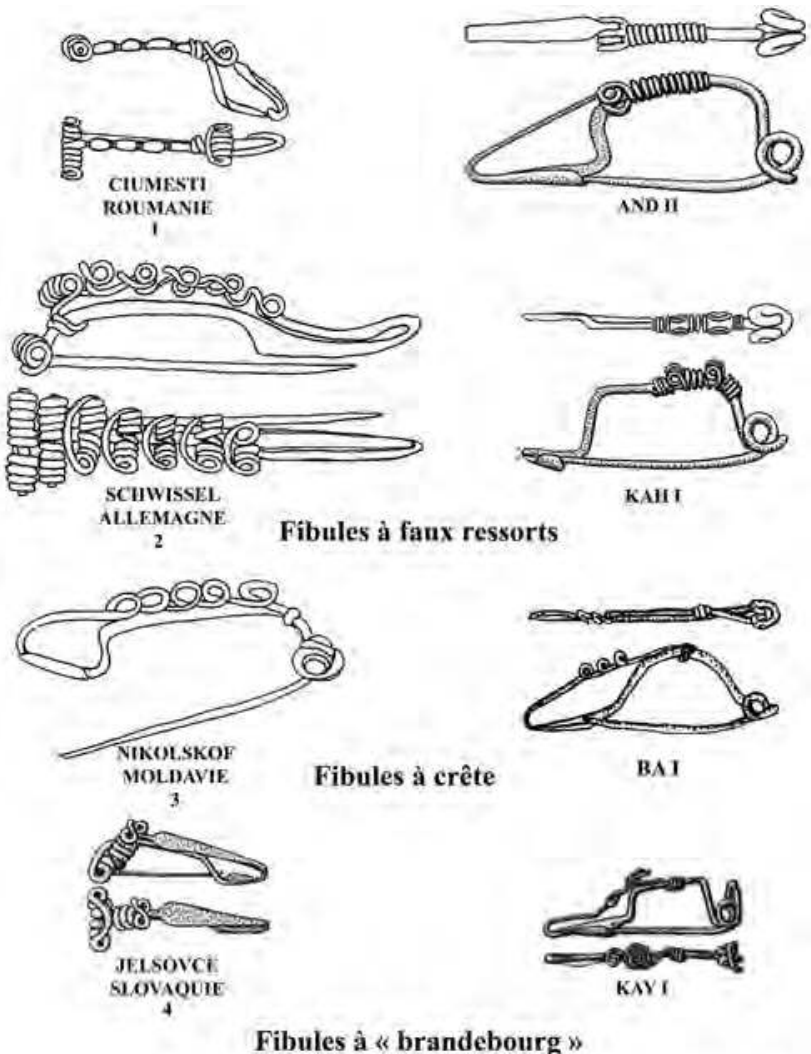

Fibules â « brandebourg "

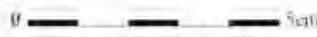

Fig. 5 : Illustration des divergences typologiques entre les fibules à épissures européennes et anatoliennes

(1- 2 : d'après Peschel 1972. 3 : d'après Shchukin 1995. 4 : d'après Szabó 1971).

Ensuite, concernant les deux fibules à épissure de notre corpus dont le pied est orné de boucles simples (BA I corpus $n^{\circ} 19$, AND I corpus $n^{\circ} 6$ ) on remarque également une évolution différente par rapport aux modèles européens. Les éléments européens les plus proches font partie d'une variante peu représentée des fibules à spirales ${ }^{39}$, variante dite "à crête" court le long de l' arc en formant une longue série de boucles. Sur les pièces d'Asie Mineure, le pied se fixe à l'avant ou au milieu de l'arc, et les boucles, qui sont moins nombreuses que sur les exemplaires européens, ne sont présentes qu'au-dessus du porte-ardillon et non le long de l'arc.

La même hypothèse d'un dérivé inspiré des styles européens peut également concerner la pièce de Kayseri KAY I (corpus n $\left.{ }^{\circ} 19\right)$. Cette pièce possède une corde externe hypertrophiée, ce qui confirme qu'il s'agit bien d'un exemplaire anatolien. Or on observe sur cette fibule un pied orné d'un "huit", style dit à "brandebourg", ornement que l'on connaît sur d'autres pièces européennes. Mais sur celles-ci, le ou les "huit" sont toujours perpendiculaires à la structure de la fibule ${ }^{41}$, comme sur la fibule de Délos (corpus $\mathrm{n}^{\circ} 1$ ). Or, sur la pièce de Kayseri, le "huit" est parallèle à la structure de la pièce. Cet ornement est par ailleurs d'autant plus particulier qu'il est composé d'un tour sur sa boucle basse et de deux tours sur sa boucle haute, dont le diamètre est supérieur à celui de la première ; on ne retrouve jamais cette dissymétrie parmi les fibules européennes. Cette pièce semble donc elle aussi répondre à un style local, influencé par les typologies européennes.

Au regard de cette analyse, nous proposons d'interpréter les fibules à épissures comme des variantes anatoliennes des types européens. Ces exemplaires répondent selon nous à un faciès laténien propre à la culture matérielle laténienne d'Asie Mineure, produit localement, et inspiré par les exemplaires européens.

Concernant les parures, on voit que le type de décor plastique que l'on trouve sur l'anneau de Finike (corpus $n^{\circ} 13$ ) ne ressemble pas aux éléments figuratifs standards que l'on observe sur les pièces laténiennes. Si les décors européens offrent une importante diversité d'ornements, trois styles principaux ont été identifiés ${ }^{42}$ : les esses, les yin-yang et les triskèles. Or, l'anneau de Finike possède un décor curviligne inédit, reprenant des motifs sinueux qui pourraient, à la rigueur, être interprétés comme un dérivé lointain de l'esse. En l'état de nos connaissances, nous voyons que le décor de cette pièce ne trouve aucun parallèle proche en Europe laténienne; nous pouvons donc proposer l'hypothèse que cette pièce soit une production locale inspirée de la tradition laténienne européenne. La même hypothèse peut être présentée pour l'anneau d'Isparta, dont la structure hybride entre une parure à nodosités et une parure à bossettes ne connaît pas de parallèle exacte en Europe, sauf éventuellement une parure de Vieille Toulouse ${ }^{43}$.

Nous voyons donc que sur les 23 fibules pour lesquelles nous disposons d'une représentation, 8 sont de type à corde externe hypertrophiée, 12 sont de type à épissure, et 2 correspondent à ces deux catégories; nous avons donc à minima 18 pièces sur

40) Popovic $2002: 146-148$.

41) Popovic $2002: 146$, Peschel $1972: 24$.

42) Kruta 1975.

43) Voir Milcent $2015: 35$. 
27 qui répondent à des typologies laténiennes spécifiques à l'Asie Mineure. Cette observation nous permet d'aller au-delà de la seule question du maintien de ces cultures matérielles laténiennes ; malgré le faible nombre de pièces connues à l'heure actuelle, nous voyons que ces cultures étaient restées suffisamment vivantes pour ne pas être une simple survivance matérielle, mais bien un élément ancré profondément, au point d'être développées et réadaptées, plusieurs générations après la rupture entre le monde laténien européen et les populations galates d'Asie Mineure.

\section{DES PHENOMENES D'ACCULTURATION ASYMETRIQUES}

Le sens d'acculturation est ambigu, car on lui prête souvent différentes acceptions. Sans ouvrir le débat, comprenons ici l'acculturation comme un concept qui insiste sur la réciprocité des dynamiques culturelles entre les groupes humains en contact. Nous entendons, à travers ce concept, parler des phénomènes de diffusion d'éléments issus de cultures matérielles allochtones, sans que cela implique, par essence, la diffusion du "sens" (culturel, politique, cultuel ou autre) de ces éléments, ou sans que cela n'entraîne nécessairement une perte de la culture d'origine. Nous nous accordons ainsi avec le sens donné à ce concept par Michel Bats :

"Il en résulte que dans le cadre de rencontres directes, et encore plus après un cheminement anonyme, le consommateur est un créateur: l'objet à travers les manipulations qu'il subit est reconstruit par son détenteur et soumis à des réinterprétations et des créations. Dans cette situation de contact entre cultures différentes, les objets viennent (ou ne viennent pas) intégrer des univers préexistants, les transformant tout en se transformant ${ }^{44}$."

Dans le cadre de notre sujet, ces phénomènes d'acculturation n'ont toujours été interprétés que comme allant des cultures matérielles autochtones vers la culture matérielle des Galates, sans jamais envisager la possible influence exercée par ces derniers sur les populations d'Asie Mineure. Or, il est possible de mettre en évidence des phénomènes d'acculturation réciproque entre les cultures matérielles galates et autochtones.

\subsection{Diffusions d'éléments laténiens hors de la Galatie}

$\mathrm{Au}$ regard de l'analyse typologique que nous avons donné de ces fibules, il est désormais possible d'interpréter différemment leur répartition géographique. Alors que les études antérieures distinguaient deux domaines de diffusion, un le long de la côte méditerranéenne au sens large et un en Anatolie centrale, il semble possible d'en identifier trois. On observe tout d'abord un domaine côtier, restreint à la côte égéenne et qui ne compte que quelques trouvailles, un second est bien visible en Anatolie là où se retrouvent les fibules à corde hypertrophiée, sur un espace correspondant peu ou prou au territoire de la Galatie, et un troisième, que l'on peut nommer "syro-cilicien", est identifiable par la concentration des pièces à épissure. Ce dernier peut également être divisé en deux, avec un domaine restreint autour d'Andırın et Pazarcık où se concentre les fibules à pseudo faux ressort, et un espace plus large, où l'on retrouve les autres types de fibules à épissures. Ce domaine large peut être étendu jusqu'à Bassit, en Syrie, au regard des caractéristiques typologiques de la pièce BA I (corpus $\mathrm{n}^{\circ} 36$ ), malgré son éloignement géographique (Fig. 6).

Cette nouvelle interprétation permet de proposer les hypothèses suivantes : tout d'abord, les deux exemplaires AM II et AM III (corpus $n^{\circ} 3$ et 4), dits "d'Asie Mineure", car sans localisation précise connue, peuvent être typologiquement rattachés au domaine syro-cilicien restreint où se retrouvent toutes les autres fibules à "faux ressorts", et donc être localisés plus précisément.

Mais surtout, cette répartition des fibules laténiennes en Asie Mineure nous permet de remettre en question les interprétations précédemment proposées pour expliquer la présence de ces fibules hors de Galatie, vues comme la manifestation archéologique d'évènements historiques, comme la guerre entre les Trocmes et le royaume de Cappadoce sous Ariarathes IV $(220-163)^{45}$ ou la présence au $2^{\mathrm{e}}$ siècle, dans la région nord-syrienne, de mercenaires galates au service de l'empire séleucide afin de protéger la frontière avec la Cappadoce ${ }^{46}$. Il est en effet préférable d'interpréter cette concentration de fibules partageant ces caractéristiques typologiques communes comme la manifestation d'une consommation voire d'une production locale de ces fibules. 
Si l'on s'accorde avec cette hypothèse, plusieurs interrogations se posent : s'agit-il d'artisans galates ayant installé leur atelier hors de Galatie? Ces pièces sont-elles des productions d'artisans locaux influencés par la culture matérielle galate? Quels sont les phénomènes qui pourraient expliquer une telle influence des Galates si loin de leur territoire ? Quoi qu'il en soit, l'existence de pièces laténiennes produites et consommées hors de la Galatie témoigne d'un phénomène d'acculturation des cultures matérielles laténiennes vers les cultures matérielles autochtones.

De plus, concernant l'interprétation des parures, nous pouvons, grâce à la pièce de Finike, envisager que l'influence des Galates sur le paysage politique anatolien ait été jusqu'ici sous-estimée. Au regard des ensembles clos retrouvés dans les nécropoles européennes, nous savons que ces parures sont strictement féminines, et sont un marqueur élitaire. Dès lors il devient difficile de lier cet objet, comme cela a été proposé, aux expéditions militaires galates. Nous proposons l'hypothèse que cette pièce soit le résultat d'un mariage entre une femme de l'aristocratie galate et un membre de l'élite autochtone. Cette hypothèse permettrait d'appréhender les relations entre Galates et autochtones autrement qu'à travers l'aspect belliqueux présenté par les auteurs anciens.

\subsection{La culture matérielle galate, une culture matérielle hybride ?}

On observe également l'intégration d'éléments issus des cultures matérielles hellénistiques dans la culture matérielle galate. Ce phénomène d'acculturation s'observe à la fois par la présence de mobilier mixte en ensemble clos et par l'identification, sur des objets typiquement hellénistiques, de marqueurs identitaires de la culture celtique.

Les fibules BOG I et II (corpus $\mathrm{n}^{\circ} 9$ et 10) ont été trouvées dans la nécropole du site de Boğazköy ; cette nécropole a également livré une troisième sépulture contenant du mobilier laténien, une panoplie d'arme composée d'une épée, d'un fourreau et d'une pointe de lance ${ }^{47}$. Ces trois sépultures se concentrent au sein de la même zone, dans l'angle sud-est de la nécropole, elles correspondent au même type d'inhumation (tombes plates avec parement en pierre, dont l'une s'inscrit dans cercle de pierres en surface) et leur datation est similaire, dans la première moitié du $1^{\text {er }}$ siècle. La présence de mobilier laténien n'est pas en soi un argument suffisant pour affirmer qu'il s'agit d'individus galates ; l'archéologie a largement démontré l'erreur de l'interprétation essentialiste "une ethnicité type = une culture matérielle type". Néanmoins, l'identification d'un geste funéraire spécifique aux populations celtes européennes dans la sépulture de la panoplie d'armes (dépôt de l'épée sur le côté droit du corps), la cohérence des sépultures entre elles, et la localisation du site en Galatie, semblent nous autoriser à envisager que nous soyons en présence de sépultures galates. Or, la sépulture contenant la fibule BOG I a également mis au jour un service à boire en sigillée composé d'un lagynos et d'un bol à boire de type hellénistique à relief, des clous de sandales militaires romaines ou caligae ainsi qu'une monnaie cappadocienne de roi Ariobarzanès I (95-63) (corpus n ${ }^{\circ} 31$ à 34). Cet exemple de mobilier mixte montre l'adoption, par les Galates, d'objets issus d'autres cultures matérielles. Cependant, avec un seul exemple par ailleurs assez tardif, il est difficile d'aller plus avant dans l'analyse.

Sur le site de Gordion, les fouilles menées sous l'égide du Penn Museum ont permis la mise au jour d'un graffiti portant un nom celtique sur un fragment de céramique ${ }^{48}$ (corpus $\mathrm{n}^{\circ} 35$ ) et d'un protomé en terre cuite représentant un buste féminin, sur lequel un torque laténien a été peint en blanc (corpus $\left.\mathrm{n}^{\circ} 36\right)^{49}$. Le graffiti porte le nom KANT[O]YI $\Xi$, transcrit Kantuix. En langue celtique continentale, nous savons grâce aux travaux de Xavier Delamarre que l'on trouve plusieurs occurrences du radical KANT : Cantiorix et Cantorix en lettres latines ${ }^{50}$, et $\operatorname{Kav} \tau v(\rho) \zeta \zeta$ en lettres grecques ${ }^{51}$. Ces noms viennent du mot gaulois canti(-), canto-, qui signifie "avec, ensemble" et qui désigne également l'assemblée ; Cantio-rix, par exemple, signifie "le roi des assemblées" 52 . De plus, il y a peu de chance que ce radical soit hérité d'une autre langue, car nous n'avons trouvé aucune occurrence de ce radical dans les études des noms grecs et indigènes en Asie Mineure ${ }^{53}$. Ce graffiti fait partie de la soixantaine d'inscriptions d'Asie Mineure portant un nom galate que nous

47) Cette panoplie d'arme sera l'objet d'une publication à part entière.

48) Roller $1987: 129$.

49) Stewart $2010: 223$.

50) Delamarre $2003: 359$.

51) Delamarre $2003: 260$.

52) Delamare $2003: 141$.

53) Robert 1963, Zgusta 1964. 


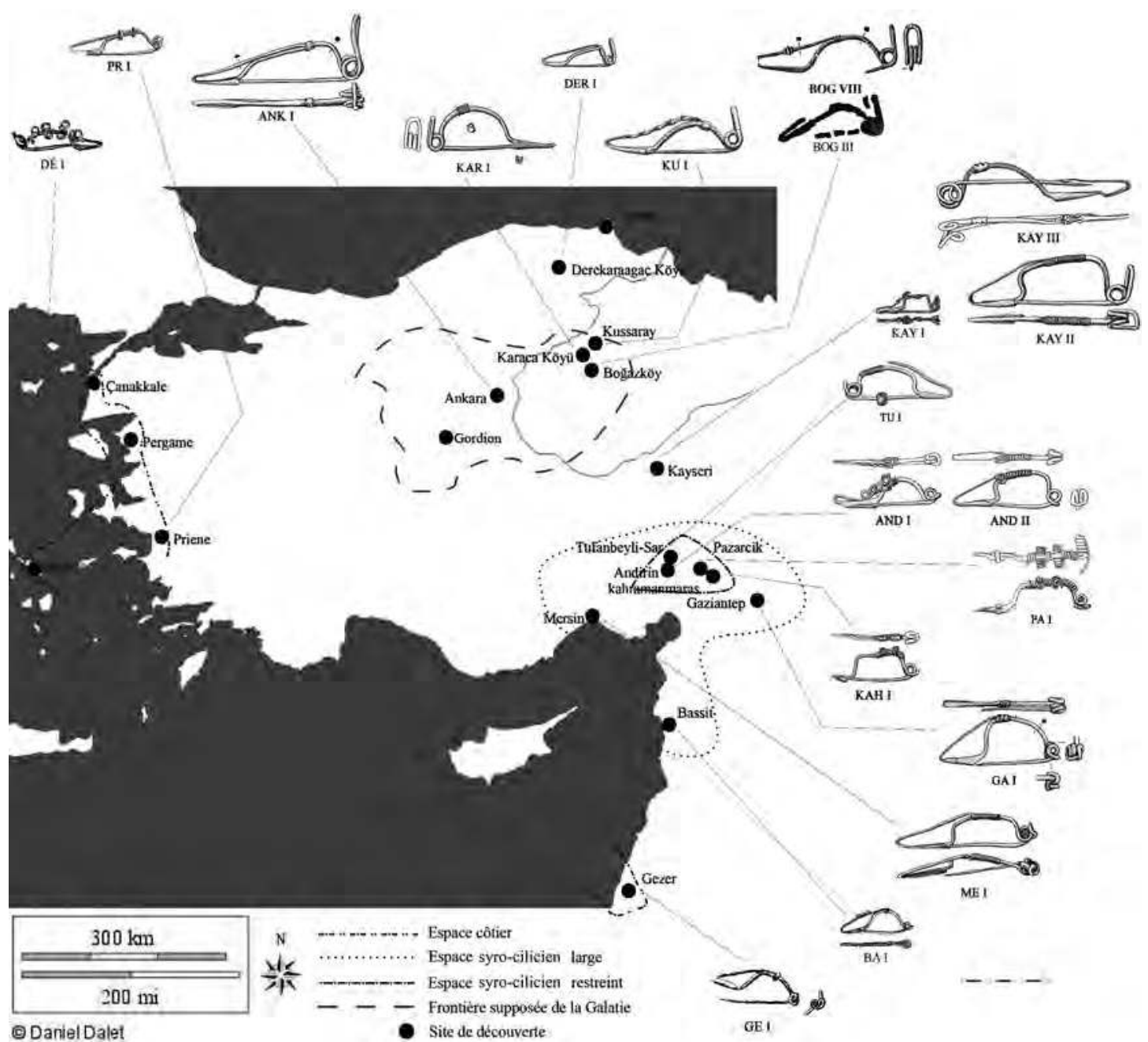

Fig. 6 : Carte de répartition des fibules laténiennes en Asie Mineure.

connaissons aujourd'hui ${ }^{54}$. On trouve bien sûr des inscriptions de noms galates en Galatie, mais ce qui est plus surprenant, c'est que ces noms se retrouvent tout autant hors de ce territoire, comme on le voit par exemple sur un mur du Gymnase de Priène ${ }^{55}$, ou sur une inscription funéraire à Ephèse ${ }^{56}$. Ces inscriptions montrent que les Galates, ou du moins une partie d'entre eux sont lettrés, qu'ils circulent en Asie Mineure hors de la Galatie, et qu'ils connaissent une forme d'intégration dans la société hellénistique, au point de fréquenter les gymnases ; la présence, en soi, de ce graffiti à Gordion, n'est donc pas étonnante.

La seconde pièce de Gordion a également été mise au jour au sein d'une structure d'habitat ${ }^{57}$. Mais si l'on regarde l'emplacement de cette pièce au sein de la structure il est indiqué qu'elle a été découverte à proximité de 2 figurines en terre cuite de Cybèle. On connaît pour l'heure 8 figurines en terre cuite de la déesse Cybèle sur le site pour la période hellénistique, ce qui en fait la seule représentation religieuse identifiée à Gordion. Cette prédominance n'est pas étonnante ; le site se trouve à $60 \mathrm{~km}$ de Pessinonte, cité centrale du culte de cette déesse. La pratique de cultes domestiques est archéologiquement attestée à l'époque hellénistique, à travers la découverte d'autels au sein des structures d'habitat. Concernant l'usage des figurines en terre cuite, la distinction entre ornement et culte domestique est plus difficile à faire, notamment en l'absence de contexte de découverte précis. Les protomés, eux aussi, se retrouvent dans les habitats, et s'ils peuvent refléter un usage

54) Freeman $2001: 23-64$.

55) Freeman $2001: 32$.

56) Freeman $2001: 33$.

57) Stewart $2010: 223$. 
ornemental, ils sont également utilisés dans le cadre des cultes domestiques ${ }^{58}$. Il est très envisageable que la présence fréquente de figurines de Cybèle, dont le culte est très important dans la région, soit liée à cette pratique.

Dès lors, comment interpréter une figurine en terre cuite, représentant une femme, peut-être une déesse, portant un torque, et dans un potentiel contexte de culte domestique ? Tout d'abord, rappelons que le port d'un torque par une divinité n'est pas quelque chose d'exceptionnel à l'époque hellénistique et à l'époque romaine. Cependant, même si la représentation n'est pas nette, on semble remarquer que la pièce de Gordion porte une forme de torque laténien, qui est par ailleurs la forme de torque par excellence des attributs de personnages celtiques dans l'art hellénistique. Le port du torque par une femme, d'autant plus dans un contexte cultuel, trouve des parallèles probants en Europe laténienne, dont les 2 principaux sont la statue de Bozouls et l'ex-voto en bois de Chamalières, en France. Proposer une interprétation assurée à partir d'une seule pièce, comme celle de Gordion, est difficile. Il est cependant nécessaire de tenir compte de ces parallèles.

Ce phénomène d'acculturation pourrait-il soutenir également l'hypothèse d'un changement plus profond, au niveau de l'identité culturelle des individus, comme le concept d'hellénisation le propose ? L'existence de cette culture matérielle hybride est-elle la matérialisation de la transformation des Galates en Gallo-Grecs ? Rien n'est moins sûr, car, le passage d'un objet d'une culture matérielle à une autre n'implique pas le passage de son sens, de sa valeur culturelle ; ce sens doit s'observer par l'identification d'autres critères, définie comme des marqueurs culturels ou identitaires.

Pour les céramiques hellénistiques de la sépulture de Boğazköy, il est possible de proposer l'hypothèse d'un sens culturel portant, non pas sur le type d'objet, mais sur son utilisation. Ces deux céramiques forment un service clairement destiné à la consommation du $\operatorname{vin}^{59}$ : un vase pour le servir et un pour le boire. Si le lagynos et le bol à relief se retrouvent épisodiquement dans des sépultures hellénistiques, il n'existe pas à notre connaissance d'association spécifique de ces deux pièces, qui n'ont pas vocation à servir lors des rites funéraires; on peut par exemple citer une sépulture de Thassos ${ }^{60}$ où l'on retrouve un lagynos, mais aux côtés de nombreuses autres céramiques sans liens avec la consommation de vin.

Or, on connaît plusieurs exemples de dépôt de céramiques à boisson en Europe laténienne, parfois même accompagnées de son contenant d'origine sous forme d'amphore ou de stamnos remplis de vin ; ce type de mobilier est en lien avec la place importante qu'occupe le vin pour ces sociétés ${ }^{61}$. Les céramiques de Boğazköy peuvent potentiellement être porteuses d'un sens culturel particulier, qui trouve une continuité après la mort par le dépôt de ces objets (et de leur valeur symbolique) dans la sépulture. Donc s'il y a bien transfert d'un objet exogène, en l'occurrence un type de céramique hellénistique, il n'y a pas nécessairement transfert de son sens culturel.

Si cet exemple reste une hypothèse, cette démonstration est bien plus assurée pour les objets de Gordion. Le tesson de bol echinus portant le graffiti avec un nom galate, est un élément classique des productions céramiques hellénistiques ${ }^{62}$. Si l'on regarde le protomé représentant une femme portant un torque, nous sommes là aussi face à une production caractéristique des terres cuites hellénistiques. Mais le sens culturel, et même dans ces deux cas le sens identitaire, est observable ici par la conservation d'un nom en langue celtique porteur d'une valeur sociale potentiellement forte, et par la possible représentation d'une divinité, en contexte domestique, qui pourrait traduire le maintien d'une pratique religieuse celtique. L'identité et le sens culturel ne sont donc pas à chercher dans les caractéristiques techniques des objets, mais dans les éléments pouvant être des marqueurs de la valeur symbolique accordée à la culture matérielle.

Pour autant, il est primordial de ne pas adopter une posture binaire ou simpliste quant à cette question extrêmement complexe qu'est la relation entre l'identité et la culture matérielle ; il est également possible d'observer la possible adoption de traits culturels exogènes chez les Galates. La monnaie en argent de la sépulture de Boğazköy a été retrouvée sur l'omoplate du côté où la tête était tournée, sous la mandibule. De fait, il est possible de proposer l'hypothèse que la pièce était à l'origine placée dans la bouche, et d'envisager ici le geste funéraire de l'obole à Charon, servant à payer le passage du Styx. Il s'agit ici d'un culte funéraire rattaché

58) Chryssanthaki-Nagle $2006: 24$.

59) Leroux $1913: 7$

60) Ghali-Kahil $1954: 242$

61) Poux 2010.

62) Roller $1987: 129$. 
à un contexte grec ou romain, clairement différent des rites funéraires connus dans le monde laténien, au sein duquel on ne connait que quelques tombes contenant des monnaies. De même, le protomé de Gordion a été mis au jour au côté de deux voire trois figurines de Cybèle, dont le lieu de culte central se trouve à Pessinonte, non loin de la cité de Gordion. Nous savons par ailleurs, grâce à des inscriptions ${ }^{63}$, que des Galates ont accédé à la prêtrise de ce culte anatolien majeur.

L'identité, et plus encore sa représentation à travers la culture matérielle, est un phénomène à la fois pluriel et mouvant. Son appréhension doit reposer sur la définition puis l'identification de marqueurs identitaires fiables, et rester prudente dans la portée de l'interprétation proposée. Néanmoins, les démonstrations proposées ici montrent que les Galates ne sont ni des Gallo-Grecs éblouis par la supériorité de la culture hellénistique, ni des barbares reclus en Anatolie centrale comme des étrangers dans leur propre territoire. Aux côtés d'une identité et d'une culture matérielle dont on observe le maintien et la vivacité jusqu'à une période tardive, il est possible de percevoir des phénomènes d'acculturation réciproques, possiblement motivés par le commerce et les liens politiques, sociaux ou religieux tissés entre les Galates et les populations locales ; nous voyons que l'intégration des Galates dans leur environnement fait d'eux une population à part entière de ce monde bouillonnant qu'est l'Asie Mineure antique.

Les nouvelles interprétations que nous avons proposées ici permettent d'ouvrir de nouvelles pistes de réflexion quant à l'étude de la culture matérielle des Galates en Asie Mineure, et quant aux méthodes à utiliser, en s'affranchissant de la subordination aux données historiques et aux présupposés identitaires. Pour autant, les analyses et les interprétations proposées dans cet article reposent sur un nombre extrêmement restreint de données ; il est impératif de ne voir ces propositions que comme des hypothèses visant à ouvrir un débat archéologique.

Par ailleurs, nous voyons que les objets de notre corpus d'étude sont presque tous intacts, très souvent en bronze et décoré. Or, l'expérience de fouille nous apprend que pour un objet de ce type nous mettons au jour une quantité importante d'objets corrodés, fragmentés et démunis de tout ornement. Cela permet de penser qu'un nombre bien plus important d'objets laténiens a déjà été découvert, mais n'a pas été identifié comme tel. Ce problème d'identification s'explique par différents aspects. Tout d'abord, peu d'archéologues qui travaillent ou qui ont travaillé dans ces régions sont connaisseurs des cultures matérielles laténiennes; ce manque de connaissances explique qu'un certain nombre de pièces se retrouve ainsi mal ou non identifié. De plus, on sait que les cultures matérielles laténiennes font usage d'une grande quantité de mobilier en fer. Ce type de mobilier est fréquemment victime, dès la fouille, d'un manque de considération voire de préservation. Ensuite, ce métal est très souvent négligé par les études archéologiques. Il semble désormais indispensable, pour une connaissance renouvelée des présences celtiques en Méditerranée orientale, de travailler à la découverte ou à la redécouverte de ces données archéologiques dont la recherche a besoin. 


\section{CORPUS DES OBJETS LATENIENS PRESENTS EN ASIE MINEURE}

1 Délos (Grèce), fibule. Musée de Délos, $\mathrm{n}^{\circ} 5502$, bronze, 6 x 2,4 cm, datation LT C2, figure DE I. Découverte lors de la fouille du portique de Philippe, lors l'exploration archéologique de Délos par l'Ecole Française d'Athènes. Fibule filiforme dont l'ornementation est formée par l'enroulement du pied sur l'arc ; il commence par un nœud simple (ou un " 8 " déformé ?), puis continu avec trois " 8 ", chacun orné en son centre d'un nœud perpendiculaire. Le pied court parallèlement le long de l'arc et ce n'est que la tige inférieure du dernier enroulement en 8 qui se greffe sur l'arrière de l'arc. Publication(s) : Deonna 1934 / Szabó 1971.

2 "Asie Mineure" (Turquie) parure annulaire. Lieu de conservation et numéro d'inventaire inconnus. Bronze, $\phi 7,2-8,8 \mathrm{~cm}$, datation LT B2 - LT C1, figure AM I. Contexte de découverte inconnu. Parure annulaire faite d'une seule pièce de bronze circulaire. Le décor est composé de 105 petites nodosités organisées en séries de trois, une sur le dessus et deux de chaque côté. Publication(s) : Müller-Karpe 2006.

3 "Asie Mineure" (Turquie) fibule. Collection privée. Bronze, 9,7 x 3,7 cm, datation LT C2, figure AM II. Contexte de découverte inconnu. Fibule filiforme à corde externe basse et ressort à deux spires. Le pied rectiligne retourne sur l'avant de l'arc trapézoïdal et est orné d'une boucle orientée vers le bas. Aujourd'hui cassé, il s'enroulait ensuite à l'origine sur toute la longueur de l'arc en formant un décor de deux faux ressorts. Publication(s) : Bittel 1969.

4 "Asie Mineure" (Turquie) fibule. Collection privée, numéro d'inventaire inconnu. Bronze, $8 \times 3,2 \mathrm{~cm}$, datation LT C2, figure AM III. Contexte de découverte inconnu. Fibule filiforme à corde externe basse et ressort à deux spires. Le pied est aplati en lamelle ; il s'enroule sur un tour sur l'avant de l'arc trapézoïdal puis forme un décor avec un faux ressort, pour finir ensuite de s'enrouler autour de la partie centrale de l'arc. Publication(s) : Bittel 1969 / Polenz 1978.

5 "Asie Mineure" (Turquie) fibule. Collection privée. Bronze, 8 x 3,8 cm, datation LT D1, figure AM IV. Contexte de découverte inconnu. Fibule filiforme à corde externe haute et ressort à deux spires. Le pied est aplati en lamelle en forme de feuille. L'arc est relativement haut et arrondi. Le pied s'accroche par une bague sur l'arrière de l'arc subtrapézoïdal. Publication(s) : Bittel 1969 / Polenz 1978.

6 Andırın (Turquie) fibule. Musée de Kahramanmaraș, $\mathrm{n}^{\circ}$ 4.115.75. Bronze, 7,4 x 2,1 cm, datation LT D1, figure AND I. Contexte de découverte inconnu. Fibule filiforme à corde externe basse, et ressort à deux spires. Le pied forme une courbe concave qui s'accroche sur l'avant de l'arc semi-circulaire en s'ornant de trois boucles orientées vers le haut. Il s'enroule sur l'arc sur deux spires espacées, il forme ensuite un décor en faux ressorts, puis s'enroule à nouveau sur trois spires sur le haut de l'arc. 1 . Publication(s) : Müller-Karpe 1988.

7 Andırın (Turquie) fibule. Musée de Kahramanmaraş, $\mathrm{n}^{\circ}$ 4.114.75. Bronze, 7,6 x 3,1 cm, datation LT C2, figure AND II. Contexte de découverte inconnu. Fibule filiforme à corde externe basse et ressort à deux spires. Le pied est aplati en lamelle. Il forme un décor avec un faux ressort puis s'enroule autour de la partie supérieure de l'arc trapézoïdal. Publication(s) : Müller-Karpe 1988.

8 Ankara (Turquie) fibule. Lieu de conservation et numéro d'inventaire inconnus. Bronze, $11,8 \times 4,2 \mathrm{~cm}$, datation LT C2, figure ANK I. Contexte de découverte inconnu. Fibule filiforme à corde externe hypertrophiée, munie d'un ressort à deux spires. Le pied rectiligne de section semi-circulaire court le long de l'arc trapézoïdal puis s'accroche à l'arrière de celui-ci au moyen d'une bague. Publication(s) : Schaaf 1970 / Polenz 1978.

9 Boğazköy (Turquie) Fibule. Musée d'Ankara, $\mathrm{n}^{\circ}$ 68/104. Fer, 9,5 x 2,7 cm, datation LT D2a, figure BOG I. Découverte dans la sépulture $\mathrm{n}^{\circ} 12$ de la nécropole dite "du grand temple", dans le quartier de l'air sud, complexe I/XII, pièce 3. Sépulture avec parement en pierres remployant les fondations des structures antérieures. Fibule filiforme à corde externe hypertrophiée, pied rectiligne orné d'une "perle" et s'accrochant par une bague sur l'avant de l'arc arrondi. Trouvée posée sur un lagynos. Publication(s) : Bittel 1969.

10 Boğazköy (Turquie) fibule. Musée d'Ankara, $\mathrm{n}^{\circ}$ 69/1108. Fer, 7,3 x 3,2 cm, datation LT D2a, figure BOG II. Découverte dans la sépulture 2/69 du site de Boğazköy. Fibule filiforme à corde externe hypertrophiée, très corrodée et fragmentée. La chronologie n'a été fixée qu'au regard de son contexte de découverte. Publication(s) : Bittel 1969 .

11 Çanakkale (Turquie) Fibule. Lieu de conservation et numéro d'inventaire inconnus. Bronze, dimensions inconnues, datation $3^{\mathrm{e}}-1^{\text {er }}$ siècle, pas de figure. Contexte de découverte inconnu. Documentée uniquement par une description dans les publications citées, nous savons uniquement qu'il s'agit d'une fibule avec le pied rattaché sur l'arc. Les pièces de Çanakkale et de Pergame sont dites semblables. Publication(s) : Jacobsthal 1941 / Polenz 1978.

12 Derekaraağaç Köyü (Turquie) Fibule. Lieu de conservation et numéro d'inventaire inconnus. Bronze, $5,3 \times 2 \mathrm{~cm}$, datation LT C2, figure DER I. Contexte de découverte inconnu. Fibule filiforme à corde externe hypertrophiée, munie d'un ressort à deux spires. Le pied rectiligne longe l'arc trapézoïdal pour s'accrocher à l'arrière de celui-ci à l'aide d'une bague. Publication(s) : Müller-Karpe 2006.

13 Finike (Turquie) Parure annulaire à oves creux. Collection privée autrichienne. Bronze, $\phi$ 5,5 $9,6 \mathrm{~cm}$, datation LT C1, figure FI I. Contexte de découverte inconnu. Parure composée de deux pièces de trois oves chacune. Au regard de son contexte de découverte inconnu et sa conservation dans une collection privée, on ne peut affirmer la provenance réelle de cette pièce. $\mathbf{P u}$ blication(s) : Schaaf 1972.

14 Gaziantep (Turquie) Fibule. Musée de Gaziantep, $\mathrm{n}^{\circ}$ 94.9.75. Bronze, 8,5 x 3,6 cm, datation LT D1, figure GA I. Contexte de découverte inconnu. Fibule fili- 


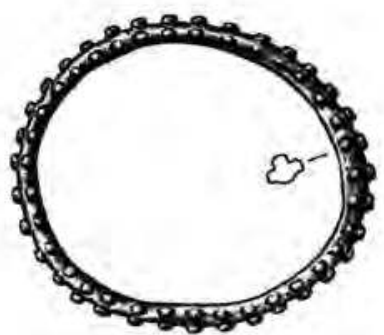

AM I

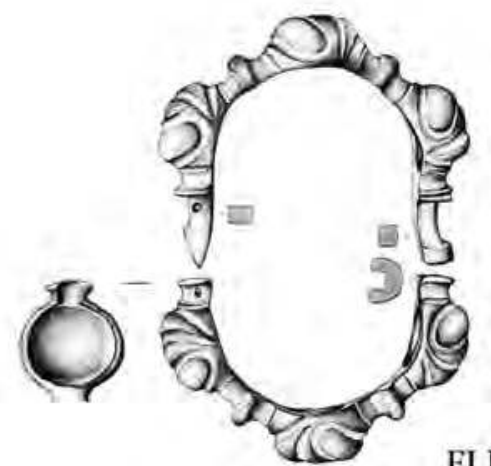

FI 1

\section{agonorocoron}

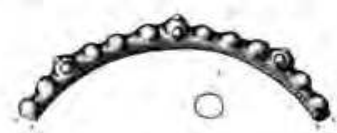

ISP I

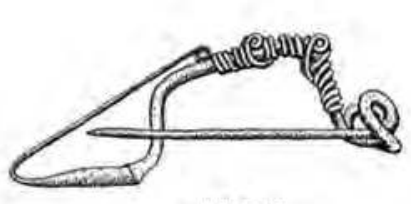

AM II

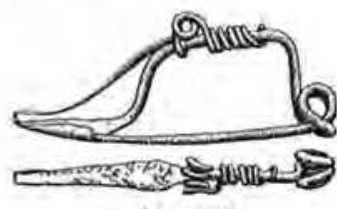

AM III
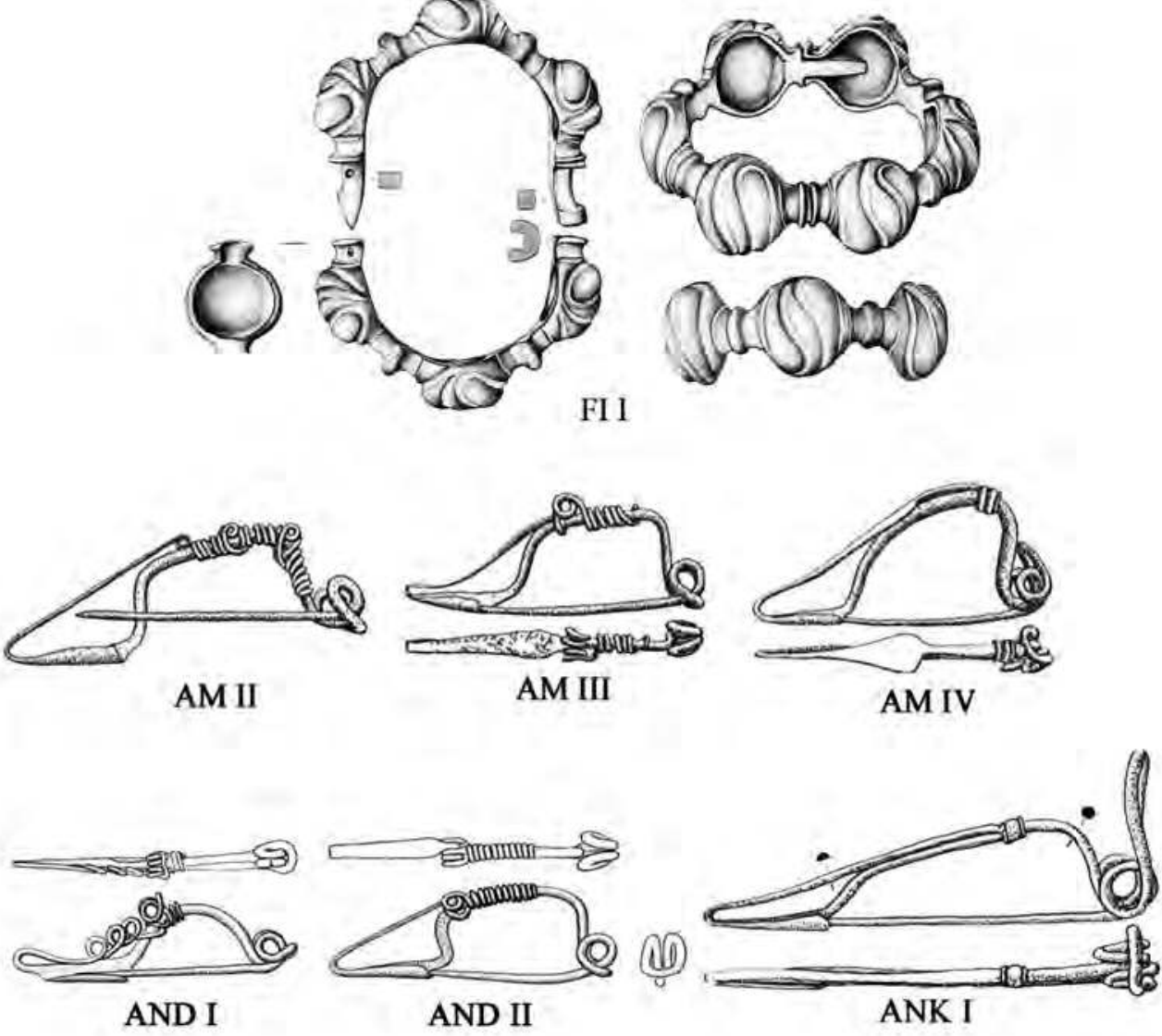

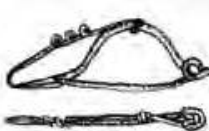

$\mathrm{BA}$ I

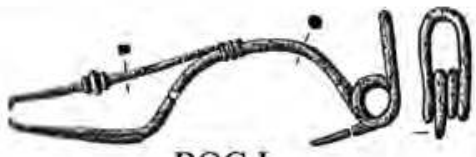

BOG I

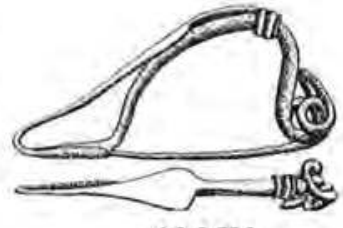

AM IV 
forme dont le ressort forme un enroulement asymétrique, où la partie externe de la corde vient former une dernière spire enroulée dans le sens inverse des précédentes. Le pied rectiligne aplani en lamelle vient s'enrouler sur trois spires à l'avant de l'arc subtrapézoïdal. Publication(s) : Bulgan et Feugère 2004.

15 Gordion (Turquie) Fibule. Lieu de conservation et numéro d'inventaire inconnus. Fer, dimensions inconnues, datation inconnue, pas de figure. Contexte de découverte inconnu. Cette pièce n'est connue que par une mention, aucune représentation n'est fournie. Publication(s) : Voigt 2002.

16 Isparta (Turquie) Parure annulaire. Musée d'Isparta, $\mathrm{n}^{\circ}$ 13-117-75. Bronze, $\phi 7,6 \mathrm{~cm}$, datation LT C1, figure ISP I. Contexte de découverte inconnu. Fragment de parure annulaire représentant environ un tiers de l'objet originel. Le décor de la parure est composé de bossettes de la largeur de l'objet. Elles sont organisées par séries de trois, chaque série étant séparée par une bossette de taille supérieure, elle-même ornée de trois petites nodosités, une sur le dessus et une de chaque côté. Publication(s) : Müller-Karpe 1988.

17 Kahramanmaraș (Turquie) Fibule. Musée de Kahramanmaraş, $\mathrm{n}^{\circ}$ 7.9.74. Bronze, 5,8 x 2,3 cm, datation LT C2, figure KAH I. Contexte de découverte inconnu. Fibule filiforme à corde externe basse et ressort à deux spires. Le pied est manquant, mais il devait à l'origine s'enrouler sur l'arc trapézoïdal. De cet enroulement subsiste la partie arrière, décorée de deux faux-ressorts. Publication(s) : Müller-Karpe 1988.

18 Karaca Köyü (Turquie) Fibule. Musée de Çorum, $\mathrm{n}^{\circ}$ 7-100-70. Bronze, 9 × 3,4 cm, datation LT D1, figure KAR I. Contexte de découverte inconnu. Fibule filiforme à corde externe hypertrophiée et ressort à deux spires. Le pied est manquant, cependant il subsiste la bague qui devait assurer son accroche sur l'arc semi-circulaire. La bague est accrochée vers les deux tiers arrière de l'arc. Publication(s) : Müller-Karpe 1988.

19 Kayseri (Turquie) Fibule. Collection privée. Bronze, 4,4 x 1,45 cm, datation LT C2, figure KAY I. Contexte de découverte inconnu. Fibule filiforme à corde externe hypertrophiée et ressort à deux spires. Le pied rectiligne est orné d'un "huit" spiralé, fait d'une première spirale d'un tour puis d'une seconde spirale de deux spires. Le pied s'enroule ensuite sur trois spires au centre de l'arc trapézoïdal. Publication(s) : Bittel 1969 / Polenz 1978

20 Kayseri (Turquie) Fibule. Musée d'Etat de Berlin, $\mathrm{n}^{\circ}$ XI b 1820. Bronze, $11,4 \times 3,35 \mathrm{~cm}$, datation LT C2, figure KAY II. Contexte de découverte inconnu. Fibule filiforme à corde externe hypertrophiée et ressort à deux spires. Le pied rectiligne aplati en lamelle très fine s'enroule en 25 spires sur la moitié centrale de l'arc trapézoïdal. Publication(s) : Polenz 1978.

21 Kayseri (Turquie) Fibule. Musée de Kayseri, numéro d'inventaire inconnu. Bronze, $13,3 \times 2,9 \mathrm{~cm}$, datation LT C2, figure KAY III. Contexte de découverte inconnu. La fibule est écrasée au niveau du pied et du ressort, la longueur d'origine doit approcher les $11 \mathrm{~cm}$. Le pied, martelé en lamelle fine, est décoré d'un motif
qu'Andreas Müller-Karpe identifie comme la représentation d'une fleur de lotus. Ce motif semble d'inspiration hellénistique. Publication(s) : Müller-Karpe 1988.

22 Kuşsaray (Turquie) Fibule. Musée de Çorum, numéro d'inventaire inconnu. Bronze, 9,5 x $3,3 \mathrm{~cm}$, datation LT D1, figure KU I. Découverte lors de la fouille du château à l'Ouest de Kuşsaray, dit "château d'oiseau". Fibule filiforme à corde externe hypertrophiée et ressort à deux spires. Le pied est torsadé et s'accroche par une bague sur l'arc semi-circulaire. Publication(s) : Koşay 1966 / Polenz 1978.

23 Mersin (Turquie) Fibule. Musée d'Etat de Berlin, $\mathrm{n}^{\circ}$ XI b 1821. Bronze et fer, 10 x $2,3 \mathrm{~cm}$, datation LT C2, figure ME I. Contexte de découverte inconnu. Fibule filiforme en bronze munie d'un ressort cassé puis réparé à une spire tournant autour d'un axe en fer. L'arc et le porte-ardillon forment un plan courbé, et l'ardillon croise l'arc en diagonale, ce qui peut être la trace d'un "bricolage". Le pied rectiligne s'enroule en quatorze spires autour du centre de l'arc trapézoïdal. Publication(s) : Bittel 1969 / Polenz 1978.

24 Pazarcık (Turquie) Fibule. Musée de Kahramanmaraş, $\mathrm{n}^{\circ}$ 13.27.79. Bronze, $8,5 \times 2,5 \mathrm{~cm}$, datation LT C2, figure PA I. Contexte de découverte inconnu. Fibule filiforme à corde externe basse. La moitié du ressort est manquante, la partie restante comporte six spires s'enroulant autour d'un axe en fer. L'ardillon et le pied sont également manquants. Le pied devait à l'origine s'enrouler sur l'arc trapézoïdal ouvert depuis l'avant, puisque subsiste le décor s'enroulant jusqu'à l'arrière de l'arc et comportant deux faux-ressorts. Publication(s) : Müller-Karpe 1988.

25 Pergame (Turquie) Fibule. Lieu de conservation et numéro d'inventaire inconnu. Bronze, dimensions inconnues, datation $3^{\mathrm{e}}-1^{\mathrm{er}}$ siècle, pas de figure. Contexte de découverte inconnu. Documentée uniquement par une description dans les publications citées, les pièces de Çanakkale et de Pergame sont dites semblables. Publication(s) : Jacobsthal 1941 / Polenz 1978.

26 Priène (Turquie) Fibule. Dernière mention au musée de Berlin-Est, ${ }^{\circ}$ MJ 10039. Bronze, 6,6 x 1,9 cm, datation LT C2, figure PR I. Contexte de découverte inconnu. Fibule filiforme à corde externe haute et ressort à trois spires. Fragmentée, le bout du pied et du porte-ardillon est manquant. La partie restante du pied rectiligne longe l'arc trapézoïdal ouvert et y est fixée par deux bagues. Publication(s) : Bittel 1969 / Polenz 1978.

27 Sinope (Turquie) Fibule. Pas de conservation ni de numéro d'inventaire. Bronze, dimensions inconnues, datation LT C2, pas de figure. Contexte de découverte inconnu. Cette fibule n'est connue que par une courte mention dans l'ouvrage cité ; elle indique que cette fibule est similaire à celle de Mersin, mais qu'il s'agit d'une pièce vue dans le commerce et que son origine n'est que supposée. Publication(s) : Bittel 1969.

28 Tufanbeyli-Sar (Turquie) Fibule. Musée de Kayseri, $\mathrm{n}^{\circ}$ 71/77-17. Bronze, 7,6 x 3,1 cm, datation LT C2, figure TU I. Contexte de découverte inconnu. Fibule filiforme à corde externe haute et ressort à quatre spires. Le pied rectiligne est cassé à son extrémité, là où 
Pl. 2

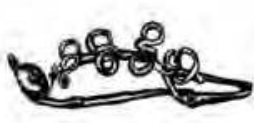

DÉ I

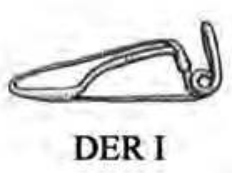

DER I
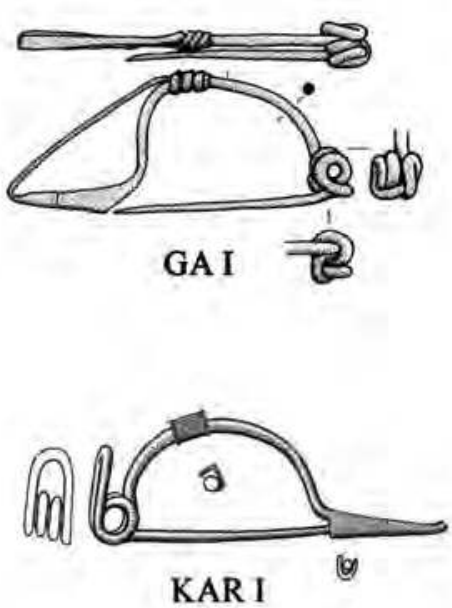

KAR I

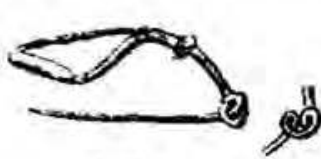

GE I
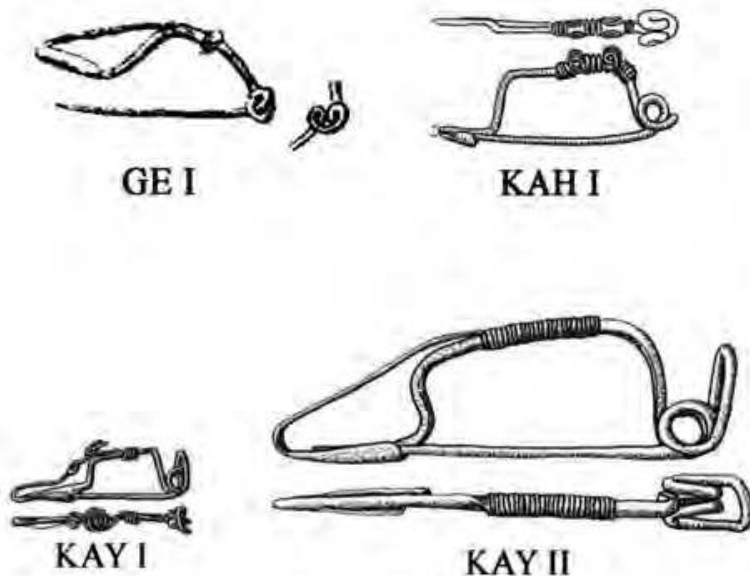

KAY II
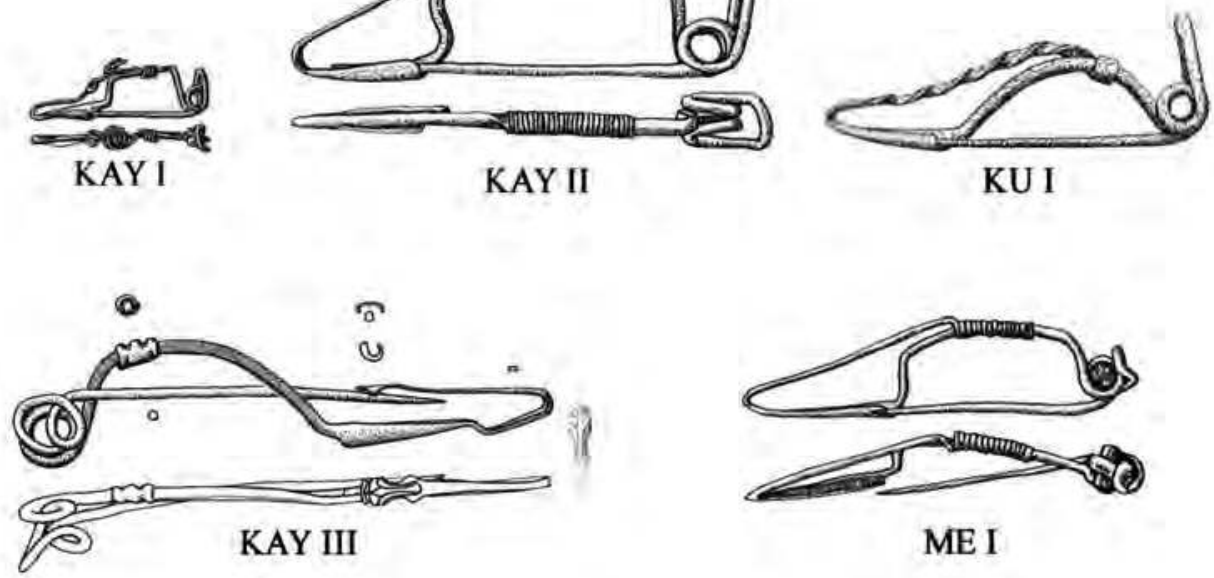

ME I

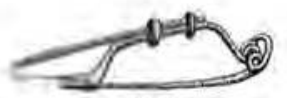

PR I

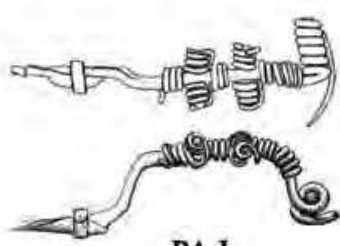

PA 1

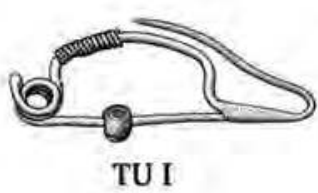

$10 \mathrm{~cm}$

DÉ I : Délos (Szabó, 1971, p. 507). DER I: Derekaraagac Köyü (Müller-Karpe, 2006, p. 121). GA I : Gaziantep (Bulgan, Feugère, 2004, p. 27). GE I : Gezer (Macalister, 1912, III p. 134, fig. 16). KAH I : Kahramanmaras (Müller-Karpe, 1988, p. 191, fig. 6). KAR I : Karaca Köyü (Müler-Karpe, 1988, p. 191, fig. 1). KAY I, II, III : Bassit (Bittel, 1969, p. 46, fig. 10g, Polenz, 1978, p. 182, Fig. 1, Müler-Karpe, 1988, p. 191, fig. 2), KU I : Kuşsaray (Bittel, 1969, p. 46, fig. 10c). ME I : Mersin (Bittel, 1969, p. 46, fig. 106). PRI I : Priène (Bittel, 1969, p. 46, fig. 10b). PA I : Pazarcik (MüllerKarpe, 1988, p. 191, fig. 7). TU I : Tufanbeyli-Sar (Müller-Karpe, 1988, p. 191, fig. 3). 

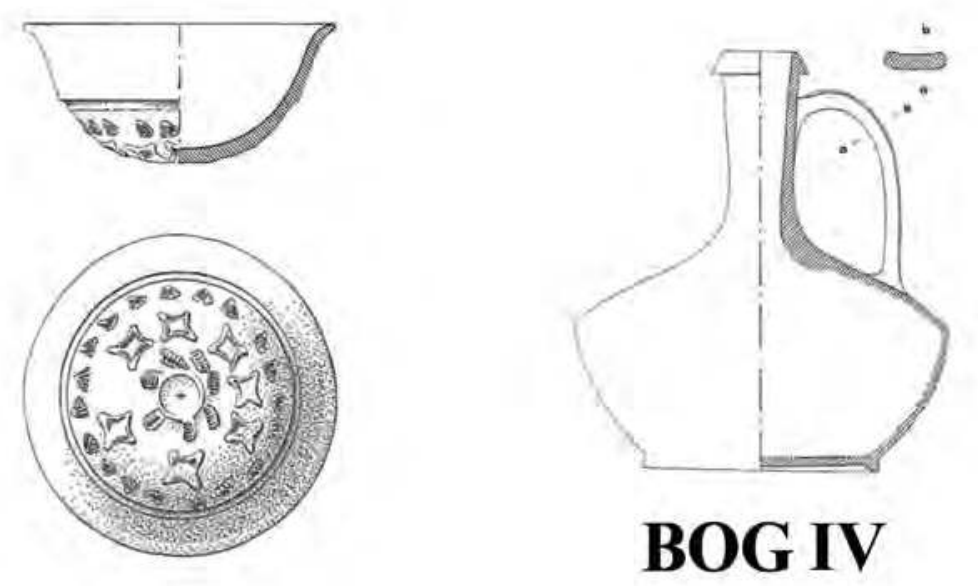

Pl. 3

\section{BOG III}

Echelle 1:4 $0=20 \mathrm{~cm}$
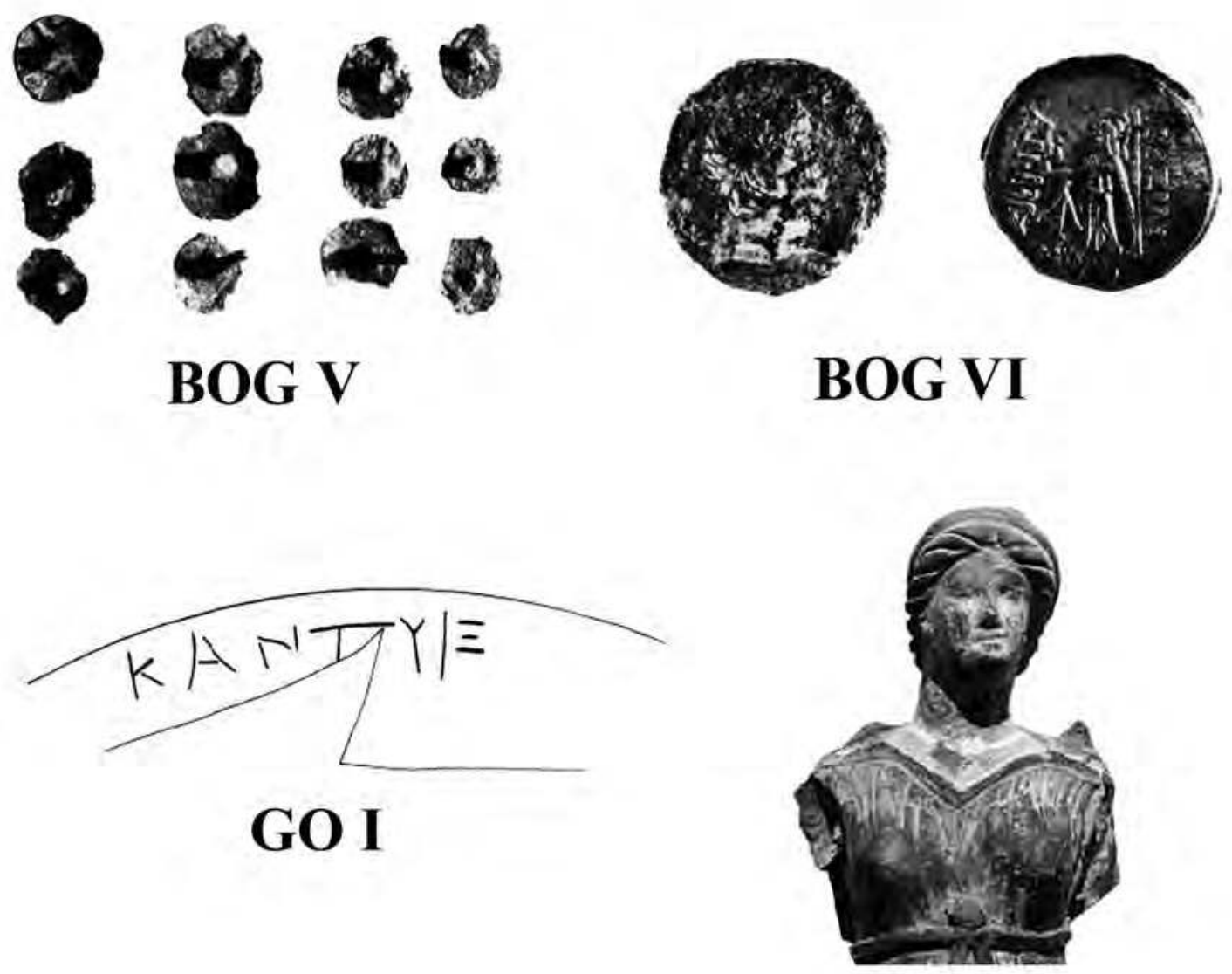

GO II

BOG III, IV, V, VI : Bogazköy, (Bittel, 1969, p. 40, fig. 8b, 8c, p. 41, fig. 8d, p. 49, fig. 12). GO I : Gordion (Roller, 1987, p.129. GO II : Gordion (Stewart, 2010, p. 421) 
à l'origine il s'enroulait en treize spires depuis le centre de l'arc trapézoïdal fermé jusqu'à sa partie arrière. Une perle en verre est enfilée sur l'ardillon. Publication(s) : Müller-Karpe 1988.

29 Bassit (Syrie) Fibule. Lieu de conservation inconnu, $\mathrm{n}^{\circ}$ V.70. Bronze, 4,9 x 1,6 cm, datation LT D1, figure BA I. Découverte lors d'une fouille programmée, dans un remblai d'époque romaine tardive contenant une part importante de matériel hellénistique. Fibule filiforme à corde externe basse et ressort à deux spires. Le pied, aujourd'hui cassé, est orné de trois boucles orien- tées vers l'extérieur. Il s'accrochait à l'origine au centre de l'arc semi-circulaire en s'enroulant sur trois épissures. Publication(s) : Courbin 1975 / Courbin 1992.

30 Gézer (Israël) Fibule. Lieu de conservation et numéro d'inventaire inconnu. Bronze, 5,8 x 1,2 cm, datation LT C1, figure GE I. Découverte dans un grand réservoir lors d'une fouille programmée du site de Gézer. Fibule filiforme à corde externe courte et ressort à deux spires. Le pied s'accroche à l'arc à l'aide de ce qui semble être une bague. L'arc est coudé. Publication(s) : Macalister 1912 / Courbin 1992.

\section{CORPUS DES ELEMENTS NON LATENIENS LIES AUX PRESENCES GALATES EN ASIE MINEURE}

31 Boğazköy (Turquie) Lagynos. Lieu de conservation et numéro d'inventaire inconnu. Sigillée, $19,6 \mathrm{~cm}$ de $\phi$ externe à la panse, 21,6 cm de haut, datation première moitié du $1^{\text {er }}$ siècle, figure BOG III. Découverte dans la sépulture $\mathrm{n}^{\circ} 12$ de la nécropole dite "du grand temple", dans le quartier de l'air sud, complexe I/XII, pièce 3. Sépulture avec parement en pierres remployant les fondations des structures antérieures. Publication(s) : Bittel 1969.

32 Boğazköy (Turquie) Bol hellénistique à relief. Lieu de conservation et numéro d'inventaire inconnu. Sigillée, $16 \mathrm{~cm}$ de $\phi$ externe à l'ouverture, 7,2 cm de haut, datation première moitié du $1^{\text {er }}$ siècle, figure BOG IV. Découverte dans la sépulture $\mathrm{n}^{\circ} 12$ de la nécropole dite "du grand temple", dans le quartier de l'air sud, complexe I/XII, pièce 3. Sépulture avec parement en pierres remployant les fondations des structures antérieures. Publication(s) : Bittel 1969.

33 Boğazköy (Turquie) 25 clous de sandales. Lieu de conservation inconnu, $\mathrm{n}^{\circ}$ 68/106. Fer, 16-18 mm de diamètre moyen, datation première moitié du $1^{\text {er }}$ siècle, figure BOG V. Découverte dans la sépulture $\mathrm{n}^{\circ} 12 \mathrm{de}$ la nécropole dite "du grand temple", dans le quartier de l'air sud, complexe I/XII, pièce 3 . Sépulture avec parement en pierres remployant les fondations des structures antérieures. Clous à tête arrondie, le motif cruciforme interne visible sur quelques pièces moins corrodées semble indiquer qu'il s'agit de clous de caligae. Publication(s) : Bittel 1969.
34 Boğazköy (Turquie) Monnaie cappadocienne d'Ariobarzanes $\mathbf{I}^{\mathrm{er}}$. Lieu de conservation inconnu, $\mathrm{n}^{\circ}$ 68/101. Argent, datation 95-63, figure BOG VI. Découverte dans la sépulture $\mathrm{n}^{\circ} 12$ de la nécropole dite "du grand temple", dans le quartier de l'air sud, complexe I/XII, pièce 3. Sépulture avec parement en pierres remployant les fondations des structures antérieures.. Publication(s) : Bittel 1969.

35 Gordion (Turquie) Fragment de céramique avec graffiti. Lieu de conservation et numéro d'inventaire inconnus. Céramique, dimensions inconnues, datation deuxième moitié du $3^{\mathrm{e}}$ siècle - premier quart du $2^{\mathrm{e}}$ siècle, figure, GO I. Découvert dans la cour d'une structure d'habitat, mont de la citadelle, secteur de la Main Excavation Area, zone de la Machteld's House. Fragment de bol echinus ( $\phi$ maximal : $12,3 \mathrm{~cm}$ ), avec un graffiti (KANT[O]YI $\Xi$, transcrit Kantuix) sur la face externe, sous la lèvre. Publication(s) : Roller 1987.

36 Gordion (Turquie) Fragment de Protomé représentant un buste féminin. Lieu de conservation inconnu, $\mathrm{n}^{\circ} \mathrm{P}-648$. Terre-cuite, dimensions inconnues, datation $3^{\mathrm{e}}-2^{\mathrm{e}}$ siècle, figure, GO II. Découvert dans une pièce d'une structure d'habitat, peut-être en contexte de culte domestique, mont de la citadelle, secteur de la Main Excavation Area, zone de la Roger's House. Représentation féminine, peut-être de divinité, avec un torque laténien peint autour du cou. Publication(s) : Stewart 2010.

\section{BIBLIOGRAPHIE}

Adam, A.-M. et Fichtl, S., 2011 : "Les Celtes dans les guerres hellénistiques: le cas de la Méditerranée orientale", in Couvenhes, Crouzet et Péré-Noguès (dirs.), Pratiques et identités culturelles des armées hellénistiques du monde méditerranéen, Actes du colloque de Tours, 23-24 mars 2007 (III ${ }^{\mathrm{e}}$ Hellenistic Warfare), Bordeaux, Ausonius : 117-128.

Baray, L., 2014 : Les mercenaires celtes et la culture de La Tène, critères archéologiques et positions sociologiques, collection art archéologie et patrimoine, Dijon, éditions universitaires de Dijon.

- 2017a : De Carthage à Jéricho Mythes et réalités $d u$ mercenariat celtique, $V^{e ̀ m e}-I^{e r}$ siècle av. J.-C., Scripta Antiqua, Bordeaux, Ausonius éditions.
- 2017b : Celtes, Galates, Gaulois-Mercenaires de l'Antiquité, collection Antiquité / Synthèses, Paris, Editions Picard.

Bats, M., 2006 : "L'acculturation et autres modèles de contacts en archéologie protohistorique européenne", Celtes et Gaulois, l'Archéologie face à l'Histoire, vol. 3. Les Civilisés et les Barbares du $V^{e}$ au II siècle avant J.-C., collection Bibracte, Glux-en-Glenne : 29-41.

- 2007 : "Entre Grecs et Celtes en Gaule méridionale : de la culture matérielle à l'identité ethnique", Identités ethniques dans le monde grec antique, acte du colloque international de Toulouse (9-11 mars 2006), Pallas $73: 235-242$. 
Bittel, K., 1969 : Boğazköy IV : Funde aus den Grabungen 1967 und 1968, Abhandlungen der Deutschen Orientgesellschaft, Berlin, Gebr. Mann.

- 1974 : "Bemerkungen zur sogenannten galatischen Keramik", Mélanges Mansel, Ankara, Türk Tarih Kurumu Basımevi : 227-237 et pl. 87-92.

Boehmer, R.M., 1969 : Die Kleinfunde von Bogazkoy aus den Grabungskampagnen 1931-1939 und 19521969, Wissenschaftliche Veröffentlichung der Deutschen Orient-Gesllschaft, Berlin, Gebr. Mann.

Brun, J.-P., Poux, M. et Tchernia, A. (dirs.) 2010 : Le vin. Nectar des Dieux, Génie des Hommes, Infolio.

Bulgan, F. et Feugère, M., 2004 : "Une fibule Galate à Gaziantep", Bulletin Istrumentum 20 : 17.

Charpy, J.-J., 2014 : "Les torques marniens de Champagne, essai de typologie", Revue du Nord 403 : 113-128.

Chryssanthaki-Nagle, K., 2006: "Les protomés et les protomés-bustes féminines de Macédoine et de Thrace revisitées : l'exemple des protomés-bustes de la maison A de Tragilos", Revue archéologique 41 : 3-31.

Courbin, P., 1975 : "Rapport sur la 4" campagne de fouilles (1974) à Ras el Bassit", Annales Archéologiques Arabes Syriennes 25.

- 1992 : "Une fibule gauloise à Bassit.", Syria 69 : 211-219.

Déchelette, J., 1908 : Manuel d'archéologie préhistorique et celtique, vol. 4. Second âge du Fer, époque de la Tène, Picard Editeur, Paris.

Delamarre, X., 2003 : Dictionnaire de la langue gauloise, collection des Hespérides, Paris, éditions Errances.

Déonna, W., 1934 : "Le mobilier délien", Bulletin de Correspondance hellénique 58 : 1-90.

Firatl, N., 1965 : "Two Galatian Tumuli in the Vicinity of Bolu", American Journal of Archaeology 69 : 365-367.

Freeman, P., 2001 : The Galatian Language. A Comprehensive Survey of the Language of the Ancient Celts in Greco-Roman Asia Minor, Ancient Near Eastern Texts and Studies, Lewiston, Edwin Mellen Press.

Ghali-Kahil, L., 1954 : "Nécropoles thasiennes", Bulletin de correspondance hellénique 78: 225-251.

Jacobsthal, P., 1941 : Kelten in Thrakien, Athenai.

Kaenel, G., 1990 : Recherches sur la période de La Tène en Suisse occidentale : analyse des sépultures, Lausanne, Cahiers d'Archéologie Romande.

Koşay, H.Z, 1966 : "Kuşsaray (Çorum) Sondajı”, Türk Arkeoloji Dergisi 15 : 89-98.

Kruta, V., 1975 : L'art celtique en Bohême. Les parures métalliques $d u V^{e}$ au II siècle avant notre ère, Librairie Honoré Champion, Paris.

Leroux, G., 1913 : Lagynos, recherches sur la céramique et l'art ornemental hellénistiques, Bobliothèque de l'Ecole des hautes études, IV ${ }^{\mathrm{e}}$ section, sciences historiques et philologiques, Paris, Ernest Leroux Editeur.

Macalister, R., 1912 : The Excavation of Gezer, Vol. II, Palestine Exploration fund publication, London, the committee of the Palestine Exploration fund.

Maier, F., 1963 : "Bemerkungen zur sogenannten galatischen Keramik von Boğazköy", Jahrbuch des Deutschen Archäologischen Instituts 78 : 218-256.
Masse, A., 2007 : "La fabrication de la parure annulaire à oves creux dans le bassin des Carpates à l'âge du fer", Actes du XXVII colloque de l'AFEAF, Clermont-Ferrand, Monographies d'archéologie méditerranéenne : 301-308.

Milcent, P.-Y., 2015 : "Le peuplement de Toulouse et de ses environs à l'Aube des Volques Tectosages", in Darles, Moret et Pailler (dirs.), Toulouse, naissance d'une ville, Toulouse, Editions Midi-Pyrénéennes : 33-38.

Müller-Karpe, A., 1988 : "Neue galatische Funde aus Anatolien", Istanbuler Mitteilungen 38: 189-199.

- 2006 : "Zur historischen Deutung von Funden keltischer Trachtelemente in Anatolien", in M. Szabó (dir.), Celtes et Gaulois : l'Archéologie face à l'Histoire, vol. 3. Les Civilisés et les Barbares du Ve au II siècle avant J.$C$., Table ronde de Budapest, 17-18 juin 2005, collection Bibracte, Glux-en-Glenne : 119-124.

Özsait, M. et Özsait, N., 2003 : "La céramique dite galate du bassin de Kizılırmak", Anatolia Antiqua XI : 329-342.

Peschel, K., 1972: "Fibeln mit Spiralfuss", Zeitschrift für Archäologie 6 : 1-42.

Pič, L., J., 1906 : Le Hradischt de Stradonitz en Bohême, Leipzig, K. W. Hiersemann, ouvrage traduit du tchèque par Joseph Déchelette.

Polenz, H., 1978 : "Gedanken zu einer Fibel vom Mittellatèneschema aus Kayseri in Anatolien", Bonner Jahrbücher 178 : 181-216.

Popović, P., 2002: "Le site laténien de Dautovac-Korićani et les fibules ornées de "boucles" ou de "huit" ("à brandebourgs")", Starinar, Nova Serija, 52 : $1-42$.

Préaux, C., 1978 : Le monde hellénistique, tome I, Nouvelle Clio, Paris, Presses Universitaires de France.

Robert, L., 1963 : Noms indigènes dans l'Asie-Mineure Gréco-Romaine, Bibliothèque archéologique et historique de l'Institut français d'archéologie d'Istanbul, A. Maisonneuve-Librairie d'Amérique et d'Orient, Paris.

Roller, L., 1987 : "Hellenistic Epigraphic Texts from Gordion" Anatolian Studies 37 : 103-133.

Schaaf, U., 1970 : "Eine 'Mittellatène' Fibel aus Kleinasien", Jahrbuch des Römisch-Germanischen Zentralmuseums 17 : 297-300.

- 1972 : "Ein keltischer Hohlbuckelring aus Kleinasien", Germania 50 : 94-97.

Stewart, S.M., 2010 : Gordion After the Knot: Hellenistic Pottery and Culture, University of Cincinnati.

Szabó, M., 1971 : "Une fibule celtique à Délos”, Bulletin de correspondance hellénique 95 : 503-514.

- 1991 (2001 réédition) : "Les Celtes et leurs mouvements au III" siècle av. J.-C.", in S. Moscati et al. (dirs.), Les Celtes, EDDL, Paris : 303-320.

Voigt, M., 2002 : "Celts at Gordion: The Late Hellenistic Settlement", Expedition 45-1 : 15-19.

Zahn, R., 1907 : “Archäologische Gesellschaft zu Berlin”, Archäologischer Anzeiger, Beiblatt zum Jahrbuch des Archäologischen Instituts.

Zgusta, L., 1964 : Kleinasiatische Personennamen, Prague, Verlag der tschechoslowakischen Akademie der Wissenschaften. 


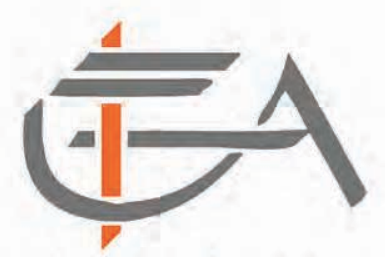

Institut Français d'Etudes Anatoliennes

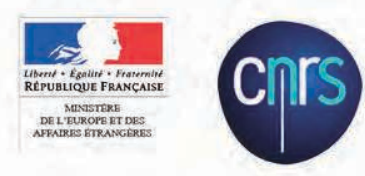

La citadelle de Tushpa (Van, Turquie).

ISBN: 978-2-36245-074-7

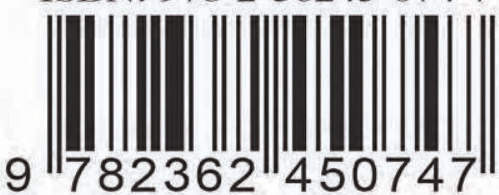

